\title{
Developing Country Second-Mover Advantage in CoMpetition Over ENVIRONMENTAL STANDARDS AND TAXES
}

\author{
by
}

Valeska Groenert, Myrna Wooders, and Ben Zissimos

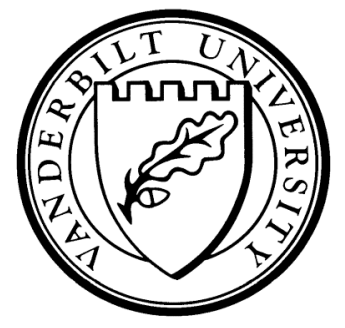

Working Paper No. 10-W12R

First version: October, 2008

Revised: October 2010

\section{DEPARTMENT OF ECONOMICS \\ VANDERBILT UNIVERSITY \\ NASHVILLE, TN 37235}

www.vanderbilt.edu/econ 


\title{
Developing Country Second-Mover Advantage in Competition over Environmental Standards and Taxes ${ }^{1}$
}

\author{
Valeska Groenert ${ }^{2}$ \\ Universitat Autònoma de Barcelona \\ Myrna Wooders ${ }^{3}$ \\ Vanderbilt University \\ Ben Zissimos ${ }^{4}$ \\ Vanderbilt University \\ First draft: October 2008 \\ Revised: October 2010
}

\begin{abstract}
We show that, in competition between a developed country and a developing country over environmental standards and taxes, the developing country may have a 'secondmover advantage.' In our model, firms do not unanimously prefer lower environmentalstandard levels. We introduce this feature to an otherwise familiar model of fiscal competition. Four distinct outcomes can be characterized by varying the marginal cost to firms of an environmental externality: (1) the outcome may be efficient; (2) the developing country may be a 'pollution haven;' a place to escape excessively high environmental standards in the developed country; (3) the developing country may 'undercut' the developed country and attract all firms; (4) the developed country may be a pollution haven.
\end{abstract}

KEYWORDS: Environmental standards, fiscal competition, second mover advantage, tax competition.

JEL Classification Numbers: H2; H3; Q2

\footnotetext{
${ }^{1}$ We would especially like to thank Sam Bucovetsky, Katherine Cuff, Amrita Dhillon, Will Strange, and three anonymous referees for detailed comments and/or conversations about this paper. We are also grateful for comments from participants at the Workshop on Stability in Competition, CORE, Louvain la Neuve, a European Science Foundation Workshop, Paris 1, a seminar at the MPI in Bonn, the Social Choice and Welfare Meeting in Istanbul, a Canadian Public Economics Group Meeting at the University of Toronto and seminars at the University of Warwick and Vanderbilt University. Funding from the Center for the Americas at Vanderbilt University, from the Spanish Ministry of Science and Innovation through grant "Consolidated Group-C" ECO2008-04756, and from the Barcelona GSE Research Network is gratefully acknowledged.

2 valeska.groenert@uab.cat

${ }^{3}$ myrna.wooders@vanderbilt.edu

${ }^{4}$ ben.zissimos@vanderbilt.edu

Dept. of Economics, Vanderbilt University, Nashville, TN 37235.

Tel: ++16153223339 .

Fax: ++16153438495 .
} 


\section{Introduction}

The recent integration of countries in Eastern Europe to the European Union (EU) has provoked renewed concern about the aggressive competition by new members for firms and other mobile factors. For example, although EU accession requirements demand moves towards harmonization of environmental standards and some measures have made it onto statute books, there appears to be widespread skepticism about the actual implementation of such measures. Citing the incentive not to raise standards in order to attract firms, Post (2002) states that "there is a "deception gap" between what is said on paper and what is done in practice' with regard to environmental policy. ${ }^{5}$

To investigate this concern, our paper develops a model of international competition over environmental standards (ESs) and taxes. Firms who locate in a country are required to pay a tax that is used, at least in part, to monitor (and enforce) the ES in that country. The main purpose of this paper is to show that, through competition in ESs and taxes, a developing/transition country may indeed have a 'second-mover advantage' over a developed country in attracting firms and extracting rents but not necessarily through the expected channels of low taxes and ESs. While this concern has circulated in policy discussions for some time now, to our knowledge it has not been studied formally before in the literature on fiscal competition.

This issue has been raised particularly with respect to the more economically successful 'transition countries' from the former Soviet Union as well as, to a lesser extent, the 'emerging market' developing countries in Asia and the Middle East. The so-called 'Visegrad countries' of the Czech Republic, Hungary, Poland and Slovakia (V4 for short) exemplify the developing and transition countries that we have in mind. These countries are in the midsts of comprehensive governmental reforms, and arguably their governments have a greater degree of flexibility and fewer constitutional and institutional constraints than the long-established democracies in the core of Europe. The same reasoning may also be used to explain the greater flexibility of dictatorships and young democracies further afield. For brevity, throughout the paper we will use 'developing country' as a catch-all term for such

\footnotetext{
${ }^{5}$ Andanova (2003) provides further details of environmental policy in Eastern Europe.
} 
countries. ${ }^{6}$ We capture this greater flexibility in policy-making by developing countries, as a result of which they can respond (within the period of a parliament say) to policies adopted by developed countries, through our specification of timing in the game of policy formation. In our two country model, we will assume that the developed country sets its standard and tax first, followed by the developing country.

In contrast to the past literature (summarized below), we focus on a situation where the tax base is not universally repelled by, nor universally attracted to, ESs. ${ }^{7}$ Consider the familiar textbook example where firms need water as an input to production and so must locate around a lake. We assume that there are two mobile firms in the model that differ in the efficiency of their production technologies. Say that one is newer than the other and, using more efficient technology, pollutes the water in the lake by less per unit of output. So the pollution emitted by the 'dirty' firm reduces the profits of the 'clean' firm more than vice versa. If they both locate in the same country (and around the same lake), an ES that requires all firms to reduce their pollution will improve the profits of the clean firm while the effect on the profits of the dirty one is ambiguous. We assume that there are two additional identical 'home' firms whose locations are fixed, one in each country, and whose technologies are dirtier than those of the mobile firms. The idea is that, in addition to lowering taxes, a government may be able to make its country more attractive to both mobile firms by raising

\footnotetext{
${ }^{6}$ It should be understood that we are excluding from consideration a significant group of transition countries and less developed countries whose economic performances remain poor, not least because their policy-making processes are bogged down in a quagmire of distributional and special-interest concerns. The World Bank's (1996) World Development Report focuses specifically on a comparison in economic performance of the transition economies, grouping the twenty-six countries by numbers 1-4, with the topperforming V4 countries in group 1, etc. Specific details substantiating the distinction we make between governments in transition countries are provided in Chapter 7 of World Bank (1996), which focuses on government and policy formation; see especially pages 113-115.

${ }^{7}$ Broadly, the prior literature on interjurisdictional competition over ESs and taxes can be categorized into two areas. The first area, following Tiebout (1956), focuses on situations where competition among independent governments is like competition among firms and enhances efficiency. Here the 'Tiebout assumption' is that all firms benefit to differing degrees from a clean environment and sort themselves efficiently into jurisdictions each of which enforces an ES that is appropriate for its members. The second area concerns the presence of a policy-failure that allows or induces governments to set taxes on mobile capital, as in the literature on fiscal federalism and 'standard tax competition' associated with Oates (1972), Wilson (1986) and Zodrow and Mieszkowski (1986). Capital is indifferent to the imposition of an ES, but is repelled if burdened with having to pay for the ES. In these situations local jurisdictions, while competing for mobile capital, at the same time tax that capital to protect the environment. In this literature, the terms 'environmental standard' and 'environmental regulation' are used interchangeably. See Wilson (1996) and Levinson (2003) for surveys. Our model combines features of models from papers in the first two categories: on the one hand competition between governments introduces efficiency enhancing incentives; on the other hand the broader environment in which these incentives operate is one of market - or policy - failures that preclude the attainment of a fully efficient equilibrium.
} 
its ES level and hence reducing the externality imposed by its home firm. ${ }^{8}$ We introduce these features to an otherwise familiar model of fiscal competition.

As the discussion so far suggests, we model competition for mobile firms as a sequential game between governments who choose standards and taxes. Due to monitoring costs, the higher the standard set by a country the more costly it is to implement. Following a common hypothesis in the literature (due to Niskanen 1977), national governments are run by bureaucrats who seek to maximize their budgets (tax revenue minus the cost of implementing the standard). To focus on competition for the mobile firms we assume that the immobile firms cannot be taxed, perhaps because they are government-owned or because they receive special treatment driven by special interests. ${ }^{9}$ A key parameter in the model is the 'marginal cost of the pollution externality' (mcpe) which parameterizes how a given pollution level affects a firm's costs of production. Each firm chooses its location to maximize profits, taking as given the tax levels and ESs in the two countries as well as the pollution levels of the other firms that locate there.

Our simple framework yields a surprisingly rich set of equilibrium predictions. There are four possible sorts of outcome which can be characterized as follows. (a) If the mcpe is low and the mobile firms are similar in their pollution levels then fiscal competition leads to an efficient equilibrium outcome (as in Brennan and Buchanan's 1980 model of tax competition). (b) If the mcpe is low but the mobile firms differ to a greater degree in their pollution levels then the developed country may set its ES inefficiently high, in which case the developing country becomes a pollution haven; a place where the dirty firm locates in order to escape the high ES set in the developed country. (c) If the mcpe is high and the mobile firms are similar in their pollution levels then the developing country is able to undercut the developed country, with both firms locating in the developing country. (d) If the mcpe is high and the mobile firms differ to a greater degree in their pollution levels then the developed country becomes the pollution haven, where the dirty firm locates to escape a (not necessarily inefficiently) high standard set by the developing country. It is especially interesting that inefficiently high standards can arise in equilibrium, either in the developed country (as in b) or in the

\footnotetext{
${ }^{8}$ We are more used to the suggestion that footloose firms are drawn to the lowest environmental standards. However, there appears to be evidence that this is not universally the case; firms that are internationally mobile are in some cases more productive through their use of more efficient and hence cleaner technologies than domestic firms and hence are attracted to higher environmental standards rather than lower ones (Graham 2000).

${ }^{9}$ Cases in point are the oil, gas, and coal mining industries whose domestic firms continue to receive subsidies throughout the EU (Euractiv 2010 and New York Times 2010).
} 
developing country (as in c and d) purely through strategic interaction between governments in their competition for firms and not as a result of attempts by governments to regulate the environment on behalf of consumers/citizens. ${ }^{10}$

The key strategic consideration that drives our results is that the developed country wants to bring about an outcome in which the developing country is prepared to 'share' the mobile firms rather than undercut the developed country and attract them both. To do so, the developed country must put the developing country in a situation where it can earn higher rents by sharing firms than by undercutting. Intuitively, sharing is particularly beneficial for the developing country if it attracts the clean firm and leaves the dirty firm to the developed country. There are two reasons to think this. The first is simply that the clean firm is cheaper to monitor since it has a lower incentive to deviate from the ES. The second more interesting effect is that the clean firm is less elastic in its location decision than the dirty firm; to avoid the relatively large externality exerted by the dirty firm it prefers to locate in the other country, and this creates extra rent that the government can extract from the clean firm through higher taxation. ${ }^{11}$

From this perspective, the most surprising equilibrium outcome is actually (b) where the developing country becomes a pollution haven, setting the minimum ES and attracting the dirty firm. In this case the developed country can make sharing firms attractive for the developing country by setting its ES at a high level and attracting the clean firm; at a low mcpe, this high ES level makes the developed country unattractive to the relatively noxious dirty firm. Consequently, the developing country can set a relatively high tax and still attract it. The precise set of interactions will be described in due course.

As mentioned above, competition between jurisdictions over standards and taxes has already received some attention in the literature. For example, Oates and Schwab (1998)

\footnotetext{
${ }^{10}$ The issue of governments setting environmental standards too high, in order to dissuade a noxious production facility from locating in their jurisdictions, is referred to as 'not in my back yard' or NIMBY, and brings about a 'race to the top'. NIMBY has been studied by Levinson (1999a,b) among others. In our framework governments do not repel firms in response to environmental concerns by consumers nor other parties who may be harmed by the hosting of firms. Yet we can get overprovision of the ES through a quite different set of interactions.

${ }^{11}$ One objection might be that developing countries typically set relatively low taxes as well as ESs whereas in our model the tax set by developing countries can be relatively high. A simple 'fix' to our model which would enable the developed country to set higher taxes would be to initially locate the mobile firms in the developed country and give them an attachment to home. This would enable us to control relative taxation across countries by varying the 'attachment to home' parameter. The reason we didn't adopt this fix was because, while the outcome would have been more realistic, the workings of the model would have been made less transparent. Other possibilities are discussed in the concluding section.
} 
consider a large number of small jurisdictions who compete in taxes and ESs to attract capital from the world capital market. Markusen, Morey and Olewiler (1995) consider a situation where two jurisdictions compete to attract the plants of a firm. ${ }^{12}$ The concern in both settings is with conditions under which competition between governments will lead to a departure from an efficient outcome. These papers make important contributions. Yet as far as we are aware, the situation that we examine here in which firms inflict pollution externalities on each other has not previously been studied in the context of fiscal competition. And the issue of developing country second-mover advantage has not formally been motivated. We will continue the discussion of how the present paper relates to the literature in Section 5 below.

The remainder of this paper is organized as follows. Section 2 introduces the model. Section 3 solves for the efficient allocation. Section 4 defines strategies and the subgame perfect equilibrium and then characterizes equilibrium in terms of the four cases outlined above. Section 5 places the paper's contribution to the literature and draws conclusions.

\section{The Model}

The governments of two countries, a developed country, $L$ (for 'leader'), and a developing country, F (for 'follower'), compete over ES levels and taxes in their attempts to induce firms to locate in their respective countries. The governments are assumed to be rent maximizers. There is a set of firms, each of which is able to sell a single unit of a good. The profits of a firm depend on the level of taxation, the level of the ES, and on the pollution levels of other firms, in the country where it locates. We will first specify the behavior of firms, and then we will turn to governments. This is the natural sequence of exposition given that we solve for equilibrium using backwards induction.

\subsection{Firms}

Each firm is able to sell its single unit at price $p$ and has a fixed private per-unit production cost, $\gamma \cdot{ }^{13}$ The tax levied on the firm is $\tau_{L}$ if it locates in $L$ and $\tau_{F}$ if it locates in $F$. Let the variables $l_{L}, l_{F} \in[0,1]$ denote the ES levels in $L$ and $F$ respectively. Let $s_{j} \in[0,1]$ denote

\footnotetext{
${ }^{12}$ Markusen et al (1995) also consider the possibility of NIMBY.

${ }^{13}$ To increase realism, the price that each firm receives for the good that it sells could be made to vary across firms without affecting the results.
} 
the per-unit-of-output pollution level of a given firm, $j .{ }^{14}$ There is an immobile 'home' firm in each country, $h$, for which $s_{h}=1$. In addition there are two mobile firms: the clean firm, $c$, with pollution level $s_{c}$; and the dirty firm, $d$, with pollution level $s_{d}$. Let $s_{c} \leq s_{d}<1$, and normalize so that $s_{c}=0$.

Firms that are located in the same country impose a nonpositive externality on each other. In the absence of any ES, the externality that a firm $s^{\prime}$ imposes on a firm $s$ depends on the pollution level of each firm as well as on a parameter $k \in \mathbb{R}_{+}$and is given as follows:

$$
k s^{\prime}(1-s)
$$

The dirtier the firm $s^{\prime}$ the larger the externality imposed on firm $s$. Moreover, the cleaner is a firm's technology, the more damage pollution by another firm does to it. The overall impact of the externality is captured by the parameter $k$; this is what we refer to as mcpe. The larger is $k$ the larger the negative impact of the pollution by other firms on a firm's profit. If the ES level in country $i$ is set at $l_{i}$ and the firm locates in country $i$, the impact of the externality imposed by $s^{\prime}$ on $s$ is reduced to

$$
k\left(1-l_{i}\right) s^{\prime}(1-s)
$$

Thus the highest ES level, $l_{i}=1$, eliminates the externality completely. If there are several polluting firms in a country the negative externalities add up. Let $M_{i}$ denote the set of firms that are located in country $i \in\{L, F\}$. Then the pollution externality suffered by firm $j$, $j \in\{c, d, h\}$, can be expressed as

$$
k\left(1-l_{i}\right) E_{i}^{j}\left(1-s_{j}\right)
$$

where $E_{i}^{j}=\sum_{m \in M_{i} \backslash j} s_{m} \cdot{ }^{15}$

Abiding by a certain ES level is costly for firms. Moreover, the dirtier the firm is, the costlier it is for that firm to abide by the ES. This property is captured in the profit function by $s_{j} l_{i}$. Thus the profit of firm $j$ that locates in country $i$ is calculated as follows:

$$
\pi(j)=p-\gamma-\tau_{i}-s_{j} l_{i}-k\left(1-l_{i}\right) E_{i}^{j}\left(1-s_{j}\right), i \in\{L, F\} .
$$

\footnotetext{
${ }^{14}$ It is understood that $s \in[0,1]$ refers to the level of pollution that a firm would emit in the absence of any ES. One way to think about this is that a given technology generates a certain amount of pollution but that an ES level, $l$, requires that a proportion of the cost of the pollution be internalized.

${ }^{15}$ Say for example that the clean firm, $s_{c}$, but not the dirty firm locates in country $i$. Then for the home firm located in that country, $E_{i}^{h}=s_{c}$, while for the clean firm $E_{i}^{c}=s_{h}$. If both the clean and the dirty firm locate in country $i$ then for the home firm $E_{i}^{h}=s_{c}+s_{d}$ and so on.
} 
To focus the analysis on location decisions, it will be assumed throughout that $p$ is sufficiently high to ensure that all firms make nonnegative profits wherever they locate. A firm locates in the country where its profits are maximized. If a firm's profits are the same in both countries we assume that it locates in $F .^{16}$

Firm $j$ may prefer one country, say $F$, in terms of the tax that it sets; $\tau_{F}<\tau_{L}$. But if the environmental standards in $L$ and $F$ and the location of the other firms are such that $s_{j} l_{F}+k\left(1-l_{F}\right) E_{F}^{j}\left(1-s_{j}\right)>s_{j} l_{L}+k\left(1-l_{L}\right) E_{L}^{j}\left(1-s_{j}\right)$, firm $j$ may nonetheless prefer to locate in $L$. Notice that, all else equal, the clean firm always prefers a higher ES level since it can only benefit from a reduction in pollution by other firms while its production technology is already as clean as possible. Moreover, unless the ES is set at the highest level, the clean firm is better off if the dirty firm locates in the other country. In contrast, the dirty firm prefers higher ES levels only if $k$ is sufficiently high. This is because it is costly for the dirty firm to abide by the ES and if the externality is not very important it makes higher profits if the ES is set at a lower level. Since $s_{c}=0$, the dirty firm is indifferent about the location of the clean firm and hence is only concerned about the level of the ES because of its own cost of compliance and the limit that the ES imposes on the externality generated by the home firm.

\subsection{Governments}

Rents are given by tax revenues minus the cost of ES-setting. We assume that a government can collect tax revenues only from mobile firms that locate in its country and not from the home firm. The pollution levels of firms located in country $i$ sum to $E_{i}=\sum_{j \in M_{i}} s_{j}$. Then the cost to government $i$ of monitoring an ES level, $l_{i} \in[0,1]$, is $E_{i} l_{i} \cdot{ }^{17}$ Thus the cost of monitoring a given ES is assumed to be proportional to the level of the ES and it is more costly to monitor the ES for dirtier firms (who have larger incentives to evade the ES). ${ }^{18}$

\footnotetext{
${ }^{16}$ This only plays a role if $k$ is relatively large and $s_{d}$ is low and ensures existence of a rent-maximizing strategy among $F$ 's strategies that attract both mobile firms. The same result could be obtained by introducing arbitrarily small indivisibilities in the strategy sets. For ease of exposition, we chose not to do that.

${ }^{17}$ Note that $E_{i}$ (with no firm-superscript) measures pollution summed across all firms that locate in country $i$. This is the relevant measure for government $i$ since it must enforce the ES in all its firms.

${ }^{18}$ It seems reasonable to assume that a higher ES level is more costly to monitor because firms' incentives not to conform increase with their levels of pollution and are likely to trigger more court cases. We would not expect our results to change qualitatively if the costs of ES setting were strictly convex instead of linear.

We have adopted a reduced-form approach to incorporating the ES monitoring costs so that the model is tractable enough to get at the questions we want to address. However, the following structural model of ES monitoring would generate the same qualitative effects. Suppose that the government sets an ES level
} 
Governments move sequentially. Government $F$ observes $l_{L}$ and $\tau_{L}$ and chooses $l_{F}$ and $\tau_{F}$ to maximize its rents. ${ }^{19}$ Here is the rent function for government $F$; the rent function for $L$ is symmetric:

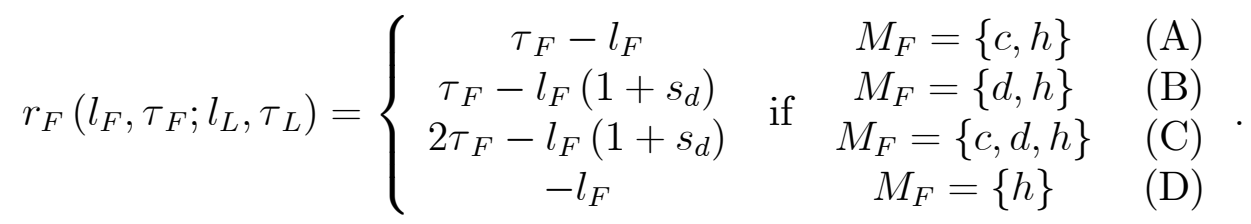

To obtain clear-cut solutions for firm locations, we need a tie-breaking rule in cases where governments might have multiple best responses. We assume that $F$ chooses sharing strategies (A or B) over undercutting strategies $(\mathrm{C})$ and sharing strategies that attract the clean firm (A) over sharing strategies that attract the dirty firm (B). ${ }^{20}$ If $L$ has multiple best responses it chooses the one with the lowest ES level and so does $F$ if indifferent among several best responses within one type of strategy. ${ }^{21}$

\section{$3 \quad$ Efficiency}

We define the efficient outcome to be the one that a social planner would choose if he could freely choose ES levels (while still having to pay the costs of monitoring) and the allocation of mobile firms to countries, but not the allocation of the immobile firms. Therefore the efficient outcome need not respect the incentives of mobile firms to change location. ${ }^{22}$ The planner is assumed to maximize the aggregate surplus realized by firms plus the governments' rents. In this section, we refer to the two countries with indices 1 and 2 since it does not matter for

of $l$ and firm $j$ has to decide on the level of pollution reduction $\rho \in[0,1]$ it undertakes, which costs the firm $\rho s_{j}$. In addition, it has to pay a fine of $\operatorname{Max}\{0, f(l-\rho)\}$ if the government inspects the firm and finds that it has violated the ES. To enforce $\rho=l$, the government has to choose a probability of monitoring the firm of at least $\operatorname{Pr}=\frac{s_{j}}{f}$. Thus, firms that have a bigger incentive to pollute need closer and hence more costly monitoring.

${ }^{19}$ For any of the following variations in the sequence of moves in our model, equilibrium in pure strategies does not exist: 1) Governments set ESs and taxes simultaneously; 2) $L$ sets an ES level, then, after learning $L$ 's choice, $F$ sets its ES level, and then, both governments simultaneously set taxes; 3) governments first simultaneously set ESs and then simultaneously set taxes. ((1) and (3) are common modeling choices in the literature on fiscal competition).

${ }^{20}$ The need for these tie-breaking rules would be removed by introducing indivisibilities into the strategy space.

${ }^{21}$ This plays a role only at single points in the parameter space of $k$ and $s_{d}$ and does not affect the qualitative nature of our results.

${ }^{22}$ The efficient outcome does not change if we assume that the planner could not freely allocate mobile firms, but would have to respect their incentives to reallocate to another country. This is because the planner can always achieve the efficient allocation of firms by setting taxes (which are welfare neutral) in a way that gives firms the incentives to choose the efficient allocation. 
the efficiency of the allocation which one is $F$ and which one is $L$. An allocation consists of two ES levels and an assignment of mobile firms to countries, denoted by $\left(l_{1}, l_{2}, M_{1}\right)$. There are only two different allocations of firms to consider: 1) The mobile firms are separated; 2) both mobile firms are allocated to the same country.

(1) Without loss of generality, let $M_{1}=\{d, h\}$. To derive the optimal ES level in country 1 solve

$$
\min _{l_{1}}\left\{\left(l_{1}+s_{d} l_{1}\right)+k\left(1-l_{1}\right)\left(1-s_{d}\right)+\left(1+s_{d}\right) l_{1}\right\} .
$$

The first term is the cost of abiding by the ES incurred by the home firm and the dirty firm in country 1 , the second term is the externality that the home firm imposes on the dirty firm, and the third term is the ES monitoring cost that the planner incurs. Solving this yields a critical level of $k=\frac{2\left(1+s_{d}\right)}{1-s_{d}}$ such that: for $k \leq \frac{2\left(1+s_{d}\right)}{1-s_{d}}$ the planner chooses the minimum ES level, $l_{1}=0$; for $k>\frac{2\left(1+s_{d}\right)}{1-s_{d}}$ the planner chooses the maximum ES level, $l_{1}=1 .{ }^{23}$ To derive the optimal ES level in country 2, where the clean firm is located, solve

$$
\min _{l_{2}}\left\{l_{2}+k\left(1-l_{2}\right)+l_{2}\right\} .
$$

The interpretation of the three terms is the same as in the previous equation but for country 2. Solving this for $k \leq 2$ yields $l_{2}=0$ and for $k>2$ yields $l_{2}=1$.

(2) Without loss of generality, let $M_{1}=\{h\}$. Thus the optimal ES in country 1 is $l_{1}=0$. To derive the optimal ES level in country 2, solve

$$
\min _{l_{2}}\left\{\left(l_{2}+s_{d} l_{2}\right)+\left(k\left(1-l_{2}\right)\left(1+s_{d}\right)+k\left(1-l_{2}\right)\left(1-s_{d}\right)\right)+\left(1+s_{d}\right) l_{2}\right\} .
$$

Solving this for $k \leq 1+s_{d}$ yields $l_{2}=0$ and for $k>1+s_{d}$ yields $l_{2}=1$.

Notice that in each of the cases just solved, there exists a critical level of $k$ such that the optimal ES level is set at minimum if $k$ is below that level and at maximum for higher levels of $k$. This critical level of $k$ is smallest in allocation (2), in which the planner allocates both mobile firms to the same country (so that the benefit of the ES is largest) and is largest if, in allocation (1), only the dirty firm is allocated to a country; that is $1+s_{d}<2 \leq \frac{2\left(1+s_{d}\right)}{1-s_{d}}$.

To decide whether it is efficient for the planner to separate firms or to locate them together in the same country, we need to compare the costs resulting from the optimal ES levels in (1) and (2). Results differ depending on the level of $s_{d}$. Table 1, in which $\left(l_{1}^{e}, l_{2}^{e}, M_{1}^{e}\right)$ denotes the efficient outcome, summarizes our results for efficiency and Figure 1 illustrates them.

\footnotetext{
${ }^{23}$ For simplicity, we select the lowest ES level if there is more than one efficient one. This is not important for the qualitative content of our results.
} 
Table 1: Efficient Outcome

\begin{tabular}{|l|c|l|l|}
\hline$k$ & $l_{1}^{e}$ & $l_{2}^{e}$ & $M_{1}^{e}$ \\
\hline$k \leq 2$ & 0 & 0 & $\{d, h\}$ \\
\hline$k \in\left(2, \frac{2 s_{d}}{1-s_{d}} \int\left(\right.\right.$ non-empty only if $\left.s_{d}>\frac{1}{2}\right)$ & 0 & 1 & $\{d, h\}$ \\
\hline$k>\operatorname{Max}\left\{2, \frac{2 s_{d}}{1-s_{d}}\right\}$ & 0 & 1 & $\{h\}$ \\
\hline
\end{tabular}

Thus, for $k \leq 2$, separation of firms with both countries setting the minimum ES is optimal. For $k>2$, it is optimal for the ES to be set at minimum in one country and maximum in the other. If $k \in\left(2, \frac{2 s_{d}}{1-s_{d}}\right]$, separation is optimal, with the clean firm located in the latter country, while if $k>\frac{2 s_{d}}{1-s_{d}}$ (or equivalently, $s_{d}<\hat{s}_{d} \equiv \frac{k}{k+2}$ ), it is optimal if both mobile firms are located together in the same country, with the ES set at maximum there. In Figure 1, $(0,0)$ refers to the fact that both countries have minimum ES levels and $(0,1)$ states that the countries have ESs $l_{1}^{e}=0$ and $l_{2}^{e}=1$ respectively. ${ }^{24}$ We say that firms are: 'Separate' when one mobile firm is located in each country and, if one country sets the maximum ES, the clean firm is located there; 'Together' when both mobile firms are located in the country that sets the maximum ES.

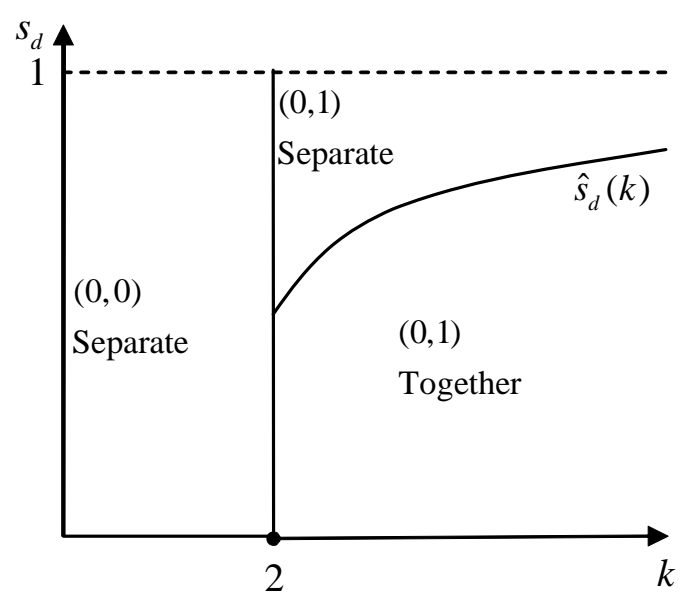

Figure 1

The efficient ES levels are weakly increasing in $k$ in the sense that for $k \leq 2$ both governments set the minimum ES levels and for $k>2$ one country sets its ES at its maximum level. Moreover, there are efficiency gains from allocating both mobile firms to the country with the maximum ES level. But these are overwhelmed if $s_{d}$ is large relative to $k$; that is if abiding by the ES is relatively costly for the dirty firm and monitoring the dirty firm is as

\footnotetext{
${ }^{24}$ There is also an equivalent efficient solution wherein $l_{1}^{e}=1$ and $l_{2}^{e}=0$.
} 
well, in which case the dirty firm is more efficiently allocated to the other country, where the ES is at its minimum level. This efficient solution will serve as a benchmark against which to compare the equilibrium outcome.

\section{Competition over Environmental Standards and Taxes}

In this section, our approach will be to first define equilibrium and then state our main theorem in which equilibrium is characterized. After that, we will provide some intuition for our results and sketch their derivation. The full proof is presented in the Appendix.

As mentioned above, ES provision and tax setting are modeled as a two-stage game. Government $L$ sets its ES level and tax and then, observing $L$ 's choices, government $F$ sets its ES level and tax. Taking government policies as given, firms then make location decisions to maximize profits. As usual, a subgame perfect Nash equilibrium is a strategy profile with the property that the governments' strategies constitute a Nash equilibrium in every subgame of the game.

A strategy for government $L$ is a pair consisting of an ES level and a tax. Formally, the set of strategies is $S_{L}=\left(l_{L}, \tau_{L}\right) \in[0,1] \times \mathbb{R}_{+}$. A strategy for government $F$ is a mapping that assigns a pair, consisting of an ES level and a tax, to each possible strategy choice made by government $L$ in the first stage of the game. Formally, this mapping is described by $f: S_{L} \rightarrow[0,1] \times \mathbb{R}_{+}$where $f\left(l_{L}, \tau_{L}\right)=\left(l_{F}, \tau_{F}\right)$. Let $\mathcal{F}$ be the set that contains all such mappings. The set of strategies for government $F$ is $S_{F}=\mathcal{F}$.

We are interested in the pure strategy subgame perfect Nash equilibrium of the game, which can be viewed as a Stackelberg game. ${ }^{25}$

Definition 2. A pure strategy subgame perfect Nash equilibrium in taxes and ES levels is a pair of strategies $\left(\left(l_{L}^{*}, \tau_{L}^{*}\right), f^{*}\right)$ such that: $(1)\left(l_{L}^{*}, \tau_{L}^{*}\right) \in S_{L}$ is a best response to $f^{*} ;(2)$ $f^{*} \in S_{F}$ and $f^{*}\left(l_{L}, \tau_{L}\right)$ is a best response to $\left(l_{L}, \tau_{L}\right)$ for all $\left(l_{L}, \tau_{L}\right) \in S_{L}$.

With the structure of the model in place and equilibrium defined, we are now ready to state our main theorem which characterizes equilibrium. For use in the theorem and as illustrated in the following figure, the function $\tilde{s}_{d}(k)$ is the boundary between cases a and b

\footnotetext{
${ }^{25}$ It will be assumed throughout that mixed strategies in tax rates are not available to governments. This is generally deemed to be an acceptable assumption in the applied literature on policy setting in a perfect information environment.
} 
of the theorem, and the function $\bar{s}_{d}(k)$ is the boundary between case $\mathrm{c}$ and cases a and d. ${ }^{26}$ Let $M_{F}^{*}$ denote the set of firms that locate in $F$ in equilibrium.

Theorem 1. The subgame perfect equilibrium is as follows.

a. (Efficient outcome) If $s_{d} \leq \tilde{s}_{d}(k)$ and $k \leq \operatorname{Min}\left\{1, \frac{3 s_{d}+1}{2\left(1-s_{d}\right)}\right\}$, both $L$ and $F$ set the minimum ES level. Firms separate with the cleaner firm locating in F. Specifically, it holds that $l_{L}^{*}=0, l_{F}^{*}=0, \tau_{F}^{*}=\tau_{L}^{*}+k s_{d}$, and $M_{F}^{*}=\{c, h\}$. The outcome is efficient.

b. (Pollution haven in $F$ ) If $s_{d}>\tilde{s}_{d}(k)$, the differentiation in ES levels between the two countries is high; $L$ sets the maximum ES level and F sets the minimum ES level. Firms separate with the dirty firm locating in F. Specifically, it holds that $l_{L}^{*}=1$, $l_{F}^{*}=0, \tau_{F}^{*}=\tau_{L}^{*}+\left(s_{d}-k+k s_{d}\right)$, and $M_{F}^{*}=\{d, h\}$. There is overprovision of the standard in $L$.

c. ( $F$ undercuts $L)$ If $s_{d}<\bar{s}_{d}(k)$ (which implies $k>\frac{1}{2}$ ), the differentiation in ES levels between the two countries is high; $F$ sets the maximum ES level and $L$ sets the minimum ES level. Both firms locate together in F. Specifically, it holds that $l_{L}^{*}=$ $0, l_{F}^{*}=1$, and $\tau_{F}^{*}=\tau_{L}^{*}-\left(s_{d}-k+k s_{d}\right)$, and $M_{F}^{*}=\{c, d, h\}$. For $k \leq 2$ there is overprovision of the standard and for $k>2$ the outcome is efficient.

d. (Pollution haven in L) If $s_{d} \geq \bar{s}_{d}(k)$ and $k>1$, the differentiation in ES levels between the two countries is high; $F$ sets the maximum ES level and $L$ sets the minimum ES level. Firms separate with the clean firm locating in F. Specifically, it holds that $l_{L}^{*}=0, l_{F}^{*}=1, \tau_{F}^{*}=\tau_{L}^{*}+k\left(1+s_{d}\right)$, and $M_{F}^{*}=\{c, h\}$. For $k \leq 2$ there is overprovision of the standard, and for $k>2$ there is underprovision for $s_{d}<\hat{s}_{d}(k)$ and the outcome is efficient for $s_{d} \geq \hat{s}_{d}(k)$.

There is always a second-mover advantage, that is rents (and taxes) are higher for $F$ than for $L$. Except for if $F$ undercuts $L$, both governments make positive rents.

${ }^{26}$ The exact expressions for these functions are as follows:

$$
\begin{aligned}
& \tilde{s}_{d}(k)=\left\{\begin{array}{c}
1-k \\
\frac{2 k}{2-2 k^{2}+k} \quad \text { if } \quad k \leq \frac{1}{2} \quad k>\frac{1}{2}
\end{array} ;\right.
\end{aligned}
$$

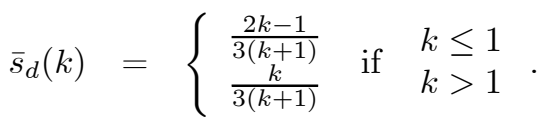


Thus all results depend on the two key parameters $k$ and $s_{d}$. (Note that the labeling of the cases as $a$ to $d$ in the theorem is unrelated to the follower's four strategies, labeled above as $A$ to $D$.) Figure 2 illustrates the theorem. The upper panel shows the four (qualitatively different) types of equilibrium; the lower panel shows whether, compared to the efficient outcome, there is too much ('Overprovision') or too little ('Underprovision') of the ES. In the figure, 'Separate' refers to the case where the clean firm locates in $F$ and the dirty firm locates in $L$ and 'Separate*' refers to the reverse case. Subgame perfect ES levels and the location of firms differ considerably across the four regions of $k$ and $s_{d}$. In the lower panel, the function $\hat{s}_{d}(k)$ separates efficiency from underprovision for $k>2 .{ }^{27}$

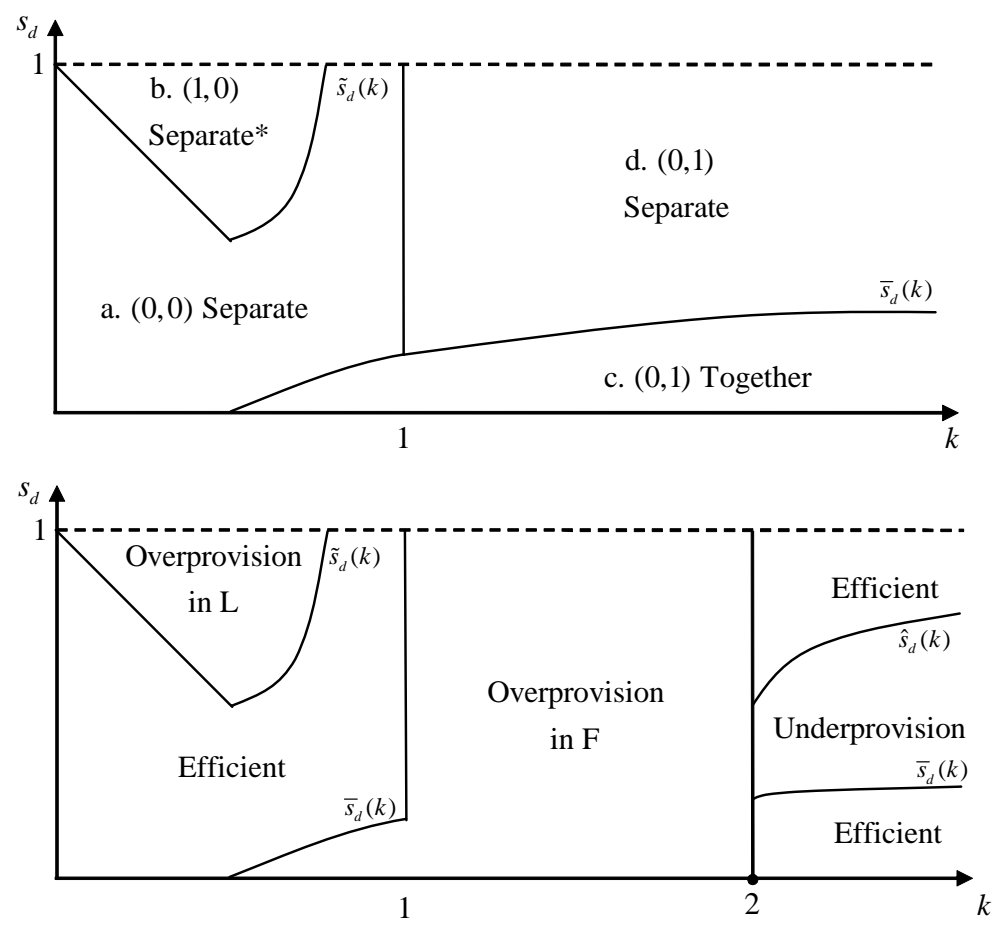

Figure 2

The key aspect that drives the results is that $L$ wants to induce $F$ to share firms rather than undercut. To do so, $L$ has to make it attractive for $F$ to share the firms by giving $F$ an incentive to incur relatively low costs of monitoring its ES and/or setting its own policy in such a way that it does not attract the firm from which $F$ would reap higher rents. In case (a), where $k$ is small and $s_{d}$ is below the threshold value $\tilde{s}_{d}(k)$, the externality is not very important for either of the firms and setting the minimum ES level is a dominant sharing

\footnotetext{
${ }^{27}$ The exact expression for $\hat{s}_{d}(k)$ is as follows:

$\hat{s}_{d}(k)=\left\{\begin{array}{c}0 \\ \frac{k}{2+k}\end{array} \quad\right.$ if $\begin{array}{l}k<2 \\ k \geq 2\end{array}$.
} 
strategy for $F$. However, even for relatively low (but still positive) $s_{d}$ the clean firm tries to avoid locating in the same country as the dirty firm, and this makes its location decision less elastic with respect to the tax than that of the dirty firm. This relative inelasticity generates rent that can be extracted from the firm by the government where it locates. To avoid being undercut $L$ attracts the dirty firm, leaving the clean firm and the associated higher rent to $F$. In case (b), where $k$ is also small but $s_{d}$ is relatively large, $L$ makes sharing an attractive strategy for $F$ by setting the maximum ES level and attracting the clean firm; this maximum ES level makes $L$ unattractive to the dirty firm, thereby allowing $F$ to extract a high tax from it. Since the efficient outcome for this parameter range is that both governments set the minimum ES level, there is overprovision in $L$. In cases (c) and (d), in which $k$ is bounded from below, attracting only the clean firm dominates attracting only the dirty firm for $F$ because the clean firm's willingness to pay not to be in the same country as the dirty firm is high relative to the cost of monitoring. Since $k$ is large, the best way to attract the clean firm is to set the maximum ES level. Given this, setting the minimum ES level is best for $L$ since this is cheap and further deters the clean firm from $L$. If, as in case $(\mathrm{d}), s_{d}$ is above $\hat{s}_{d}(k)$, $L$ is successful at inducing $F$ to attract only the clean firm. For $k \leq 2$, this means that $F$ sets an inefficiently high standard, while for higher levels of $k$ and $s_{d}$ below $\hat{s}_{d}(k)$ (but above $\left.\bar{s}_{d}(k)\right)$ there is 'underprovision' of the ES in the sense that the dirty firm goes unmonitored and would be more efficiently allocated to $F$, where the ES is set at the maximum level. In contrast, if $s_{d}$ is low, as in case (c), $L$ does not succeed in making sharing firms sufficiently profitable for $F$. Undercutting dominates attracting only the clean firm as the two firms are similar in their preferences and the maximum ES level eliminates the pollution externality between them. For $k \leq 2$, this means that $F$ sets an inefficiently high ES level, while the outcome is efficient for higher levels of $k$.

The common characteristic of equilibrium across all levels of $k$ and $s_{d}$ is that there is a second-mover advantage in that $F$ is always able to extract more rents than $L$. Both governments make positive rents, except for $L$ in case (c) where $s_{d}$ is relatively low and $k$ relatively large. The ability to extract rents arises as a result of the monopolistic power that each government has over location within its country. Each firm must locate in one country or the other in order to produce, and the government of the country where it does locate is able to exploit its resultant power when setting taxes. In the following two subsections we discuss in more detail the strategic considerations of the two countries. 


\subsection{The Developing Country}

The government of the developing country, $F$, given a strategy $\left(l_{L}, \tau_{L}\right)$ by $L$, chooses between four basic strategies: (A) attract the clean firm but not the dirty one, (B) attract the dirty firm but not the clean one, (C) attract both mobile firms, and (D) do not attract either of the mobile firms. We show in the appendix that $F$ never chooses a strategy in D. ${ }^{28}$ To find the optimal strategy, we first determine the optimal strategy within each of the remaining three types of strategies and then compare the payoffs from each.

A) Attracting only the clean firm.

To do so for a given $\left(l_{L}, \tau_{L}\right), F$ must choose $\left(l_{F}, \tau_{F}\right)$ so that if the clean firm locates in $F$ and the dirty firm locates in $L$, neither firm has an incentive to move to the other country. Thus we need

$$
\begin{aligned}
\tau_{F}+k\left(1-l_{F}\right) & \leq \tau_{L}+k\left(1-l_{L}\right)\left(1+s_{d}\right), \text { and } \\
\tau_{L}+s_{d} l_{L}+k\left(1-l_{L}\right)\left(1-s_{d}\right) & <\tau_{F}+s_{d} l_{F}+k\left(1-l_{F}\right)\left(1-s_{d}\right),
\end{aligned}
$$

or

$$
\begin{aligned}
\tau_{F} & \in\left(A^{\prime}, A^{\prime \prime}\right] \\
& \equiv\left(\tau_{L}+\left(l_{L}-l_{F}\right)\left(s_{d}-k+k s_{d}\right), \tau_{L}+k\left(l_{F}+s_{d}-l_{L}\left(1+s_{d}\right)\right)\right]
\end{aligned}
$$

B) Attracting only the dirty firm.

In a similar fashion as for case $\mathrm{A}$, we get

$$
\begin{aligned}
\tau_{F} & \in\left(B^{\prime}, B^{\prime \prime}\right] \\
& \equiv\left(\tau_{L}+k\left(l_{F}-l_{L}-s_{d}+l_{F} s_{d}\right), \tau_{L}+\left(l_{L}-l_{F}\right)\left(s_{d}-k+k s_{d}\right)\right] .
\end{aligned}
$$

C) Attracting both mobile firms.

Here, we obtain

$$
\begin{aligned}
\tau_{F} & \leq \operatorname{Min}\left\{C^{\prime}, C^{\prime \prime}\right\} \\
& \equiv \operatorname{Min}\left\{\tau_{L}+k\left(l_{F}-l_{L}-s_{d}+l_{F} s_{d}\right), \tau_{L}+\left(l_{L}-l_{F}\right)\left(s_{d}-k+k s_{d}\right)\right\} .
\end{aligned}
$$

\footnotetext{
${ }^{28}$ The brief argument is as follows. By setting the minimum ES level and a sufficiently high tax (that deters both mobile firms) $L$ can always ensure nonnegative rents. Therefore, it is sufficient to consider strategies where $L$ sets a tax that covers its costs. For any such strategy, it can be shown that $F$ has a best response that leads it to earn positive rents. Since a strategy in D leads to at most zero rents, such strategies are not chosen by $F$ in equilibrium.
} 
Define $t_{A} \equiv A^{\prime \prime}, t_{B} \equiv B^{\prime \prime}\left(=A^{\prime}=C^{\prime \prime}\right)$ and $t_{C} \equiv C^{\prime}\left(=B^{\prime}\right)$, which are all linear functions of $l_{F}$. Table 2 lists the intercepts, $\alpha_{j}$, and slopes, $\beta_{j}$, of $t_{j}$, for $j \in\{A, B, C\}$. These have natural interpretations that will be discussed below.

Table 2

\begin{tabular}{|l|l|l|}
\hline$j$ & $\alpha_{j}$ & $\beta_{j}$ \\
\hline$A$ & $\tau_{L}-k l_{L}+k s_{d}\left(1-l_{L}\right)$ & $k$ \\
\hline$B$ & $\tau_{L}-k l_{L}+l_{L} s_{d}(1+k)$ & $k-s_{d}(1+k)$ \\
\hline$C$ & $\tau_{L}-k l_{L}-k s_{d}$ & $k+k s_{d}$ \\
\hline
\end{tabular}

It is easy to see that

$$
\begin{aligned}
& \alpha_{C} \leq \operatorname{Min}\left\{\alpha_{A}, \alpha_{B}\right\}, \text { where } \alpha_{A}<\alpha_{B} \Leftrightarrow l_{L}>\frac{k}{1+2 k}, \text { and } \\
& \beta_{B} \leq \beta_{A} \leq \beta_{C} .
\end{aligned}
$$

Figure 3 depicts the different strategy sets for the two cases $l_{L} \leq \frac{k}{1+2 k}$ (left panel) and $l_{L}>\frac{k}{1+2 k}$ (right panel). To find the optimal strategy within each of the subsets $F$ chooses a standard level and the matching maximum tax in the strategy subset (where, in the figure, this is the tax at the upper boundary of the respective set). From F's rent function we have:

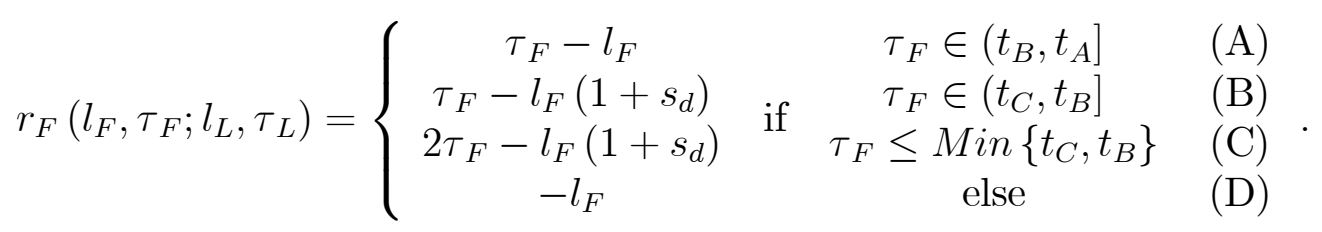

A few useful things about the optimal strategy can be seen from the rent function and Figure 3 right away. First, since setting an ES level is more costly for $F$ if it attracts the dirty firm (B) instead of the clean firm (A), and since for $l_{L} \leq \frac{k}{1+2 k}$, the maximum tax $F$ can set in $\mathrm{A}$ is always at least as high as the one in $\mathrm{B}\left(\alpha_{A} \geq \alpha_{B}\right.$ and $\left.\beta_{A} \geq \beta_{B}\right)$, all strategies in $\mathrm{B}$ are dominated. Second, if the maximum tax $F$ can set decreases in the standard, raising the standard can only decrease $F$ 's rent. The $\left(l_{F}, \tau_{F}\right)$ combinations that are potential best responses, taking into account the two observations just made, are indicated by bold lines in Figure 3. ${ }^{29}$

\footnotetext{
${ }^{29}$ Note that although $t_{C}$ lies below $t_{A}$ and (for some $l_{F}$ ) $t_{B}$, setting $t_{C}$ can potentially yield a higher rent since it attracts both mobile firms instead of only one.
} 

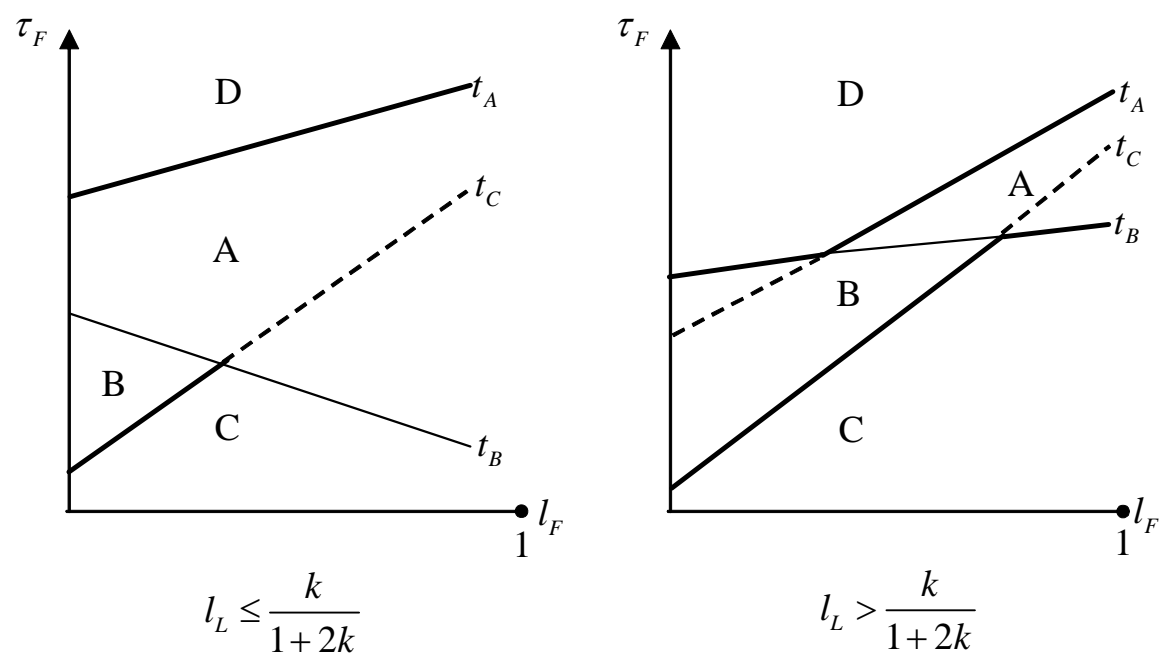

Figure 3

Taking strategies in $B$ as an example, let us consider the trade-off $F$ faces when choosing an ES level. For each of the three kinds of strategies, this trade-off is summarized in the intercepts $\alpha_{j}$ and slopes $\beta_{j}$, for $j \in\{A, B, C\}$. If the government of $F$ wishes to attract the dirty firm and set an ES of zero, the maximum tax it can set is $\alpha_{B}=\tau_{L}+s_{d} l_{L}-k l_{L}\left(1-s_{d}\right)$. For any larger tax the dirty firm would prefer to locate in $L$. $F$ can charge $\tau_{L}$ plus $s_{d} l_{L}$, the cost of abiding by the ES that the dirty firm faces in $L$, minus $k l_{L}\left(1-s_{d}\right)$, the dirty firm's cost reduction in $L$ due to the ES there. If $F$ sets a positive ES level of $l_{F}$ instead, it has to modify the tax by $l_{F} \beta_{B}=l_{F}\left(k\left(1-s_{d}\right)-s_{d}\right)$, the dirty firm's cost reduction due to the ES, $k l_{F}\left(1-s_{d}\right)$, minus its cost of abiding by the standard, $l_{F} s_{d}$. Similarly, if $F$ wishes to attract the clean firm, it has to take into account the clean firm's incentive to locate in $L$ instead. If $F$ wishes to attract both firms the incentives of only one of the mobile firms constitute a binding constraint on the maximum tax $F$ can set: In the figure, if the upper boundary of $\mathrm{C}$ borders with $\mathrm{B}$ (as is the case for low $l_{F}$ ) it is the clean firm whose incentives matter, because it has a strong incentive to escape the externality it suffers from the presence of the dirty firm; if the upper boundary of $\mathrm{C}$ borders with $\mathrm{A}$ (as is the case for large $l_{F}$ ), it is the dirty firm whose incentives matter, because it has a strong incentive to escape the high cost of abiding by the ES.

To find the rent maximizing ES level in each of the three cases, $F$ compares the marginal willingness to pay for the standard of the firms it wishes to attract with its own marginal cost of monitoring the standard, which is 1 in case $A$ and $\left(1+s_{d}\right)$ in $B$ and $C$. Since a mobile 
firm's marginal willingness to pay increases as the externality becomes more important, that is as $k$ increases, the optimal ES level for each of the three cases is weakly increasing in $k$. In contrast, the optimal ES level is weakly decreasing in $s_{d}$, the degree to which the mobile firms differ.

The last step to find F's best response is to compare rents from the optimal strategies in

each of the three cases. Since, for $l_{L} \leq \frac{k}{1+2 k}, A$ dominates $B$ it only remains to compare $A$ and $C$. Since in $C$, government $F$ collects the tax twice and the maximum tax it can charge increases with $\tau_{L}$ by the same rate in both cases (as can be seen from the intercepts $\alpha_{A}$ and $\alpha_{C}$ in Table 2), eventually with sufficiently large $\tau_{L}$, the rent-maximizing strategy in $C$ yields higher rents than the rent-maximizing strategy in $A$. Thus there is a critical level of $L$ 's tax, $\hat{\tau}_{L}\left(l_{L} ; k, s_{d}\right)$, which we call the sharing tax limit, such that $F$ attracts the clean firm up to that tax (i.e. it 'shares' firms with $L$ ) and undercuts if $L$ 's tax exceeds $\hat{\tau}_{L}\left(l_{L} ; k, s_{d}\right)$. (This is not immediate from Figure 3 but will be illustrated in the next subsection). Similarly, if $l_{L}>\frac{k}{1+2 k}$, there is such a sharing tax limit. Up to this tax $F$ shares firms, by attracting only the clean firm for lower levels of $l_{L}$ and only the dirty firm for higher levels of $l_{L}$.

\subsection{The Developed Country}

The government of the developed country, $L$, can only make positive rents if it can induce $F$ to share firms. Thus $L$ has to choose a tax that does not exceed the sharing tax limit. Since rents are increasing in taxes $L$ will choose $\tau_{L}=\hat{\tau}_{L}\left(l_{L} ; k, s_{d}\right)$. It only remains to determine the optimal ES level. In determining this level, $L$ takes into account two aspects. First, $L$ tries to find an ES level at which, compared to undercutting, sharing is particularly beneficial for $F$ so that the sharing tax limit is high. Second, $L$ takes into account the cost of monitoring the ES. Figure 4 shows the sharing tax limit (the solid line) and the cost of monitoring the ES (the dashed line) at four different combinations of $s_{d}$ and $k$, one for each of the four different equilibrium outcomes. The leader chooses the level of $l_{L}$ where the difference between the sharing tax limit and monitoring costs is maximized. If $\hat{\tau}_{L}\left(l_{L} ; k, s_{d}\right)$ is always at or below its monitoring cost $L$ cannot make positive rents (as in case c). 

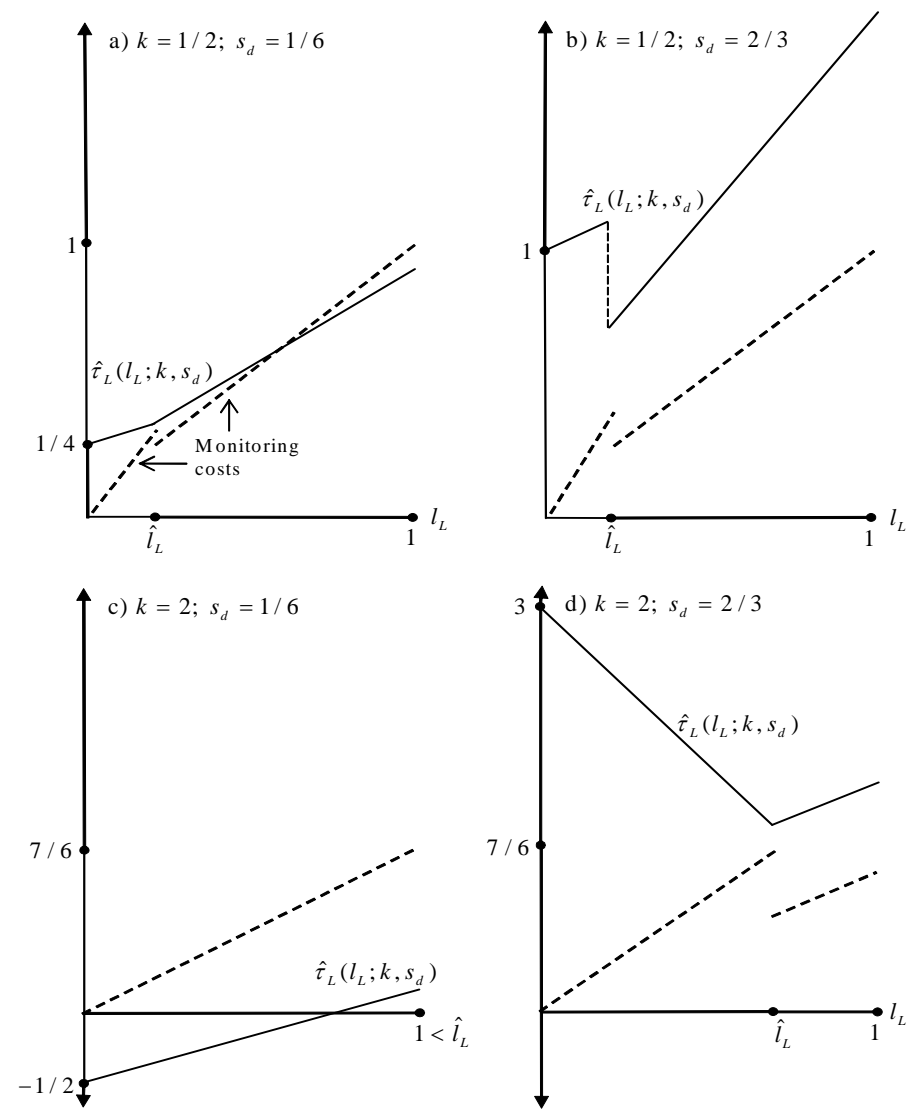

Figure 4

The monitoring costs are easily understood. Since there is a critical level $\hat{l}_{L}$ (possibly larger than 1 such as in case c) whereby $F$ attracts (only) the clean firm for $l_{L} \leq \hat{l}_{L}$ and (only) the dirty firm for $l_{L}>\hat{l}_{L}$, monitoring costs up to $\hat{l}_{L}$ are given by $\left(1+s_{d}\right) l_{L}$ and above by $l_{L}$. As can be seen in the figure the sharing tax limit, which reflects how high a tax $L$ can set without making undercutting more profitable than sharing for $F$, varies considerably with the parameters $k$ and $s_{d}$ and also with $l_{L}$. In the following, we discuss how these differences come about and how they lead to the four different types of outcome.

First, suppose that the mcpe is relatively low. To illustrate what happens if $s_{d}$ increases, keeping $k$ fixed, let us compare case a with case b in Figure 4. Suppose that $L$ sets a large ES level to attract the clean firm. For large $s_{d}$ (case b), that is if the dirty firm pollutes at a high level, $F$ can extract a high tax from the dirty firm since the high ES level in $L$ has a strong repellent effect on this firm. At the same time, attracting both firms is expensive 
for government $F$ since the clean firm suffers a large negative externality in the presence of the dirty firm and is tempted by the high ES level in $L .{ }^{30}$ This leads to a large sharing tax limit for high levels of $l_{L}$. In contrast, for small $s_{d}$ (case a), the dirty firm needs bigger tax incentives to stay in $F$ because the high ES level in $L$ is not very costly for it to abide by, and reduces the externality from the home firm. At the same time, for low $k$ and $s_{d}$, there is no strong force that keeps the two mobile firms apart and attracting both firms is not very costly. Therefore the sharing tax limit is small for small $s_{d}$. In summary, if the mcpe is relatively small, a large ES level pays off for $L$ if $s_{d}$ is sufficiently large, but not otherwise.

The critical level of $s_{d}\left(\hat{s}_{d}\right.$ in Figure 2), above which it pays off for $L$ to attract the clean firm, depends on $k$ as well. In particular, for sufficiently large $k$, this critical level is never attained. To see this, suppose that $s_{d}$ is relatively large, and consider an increase in $k$ (as if moving from case b to $\mathrm{d}$ in Figure 4). Suppose $L$ sets a low ES to attract the dirty firm. A large $k$ and $s_{d}$ together with the low ES level in $L$ have a strong repellent effect on the clean firm so its willingness to pay to locate in $F$ is large. Therefore $F$ can extract a high tax from the clean firm. At the same time, attracting both firms requires the highest ES level (because of the large marginal cost of the pollution externality), and a relatively low tax, because the high $s_{d}$ gives the dirty firm a stronger incentive to locate in $L$ where the ES level is low. Thus the sharing tax limit is high at low levels of $l_{L}$. In contrast, setting a large ES level to induce $F$ to attract the dirty firm is difficult since for sufficiently large $k$ even the dirty firm prefers, all else equal, larger ES levels. So $F$ would set a high ES level as well and compete with $L$ via taxes. However, if $F$ already sets a high ES level and a competitive tax, it might just as well in addition attract the clean firm (and since the clean firm does not need to be monitored, this is not costlier than attracting only the dirty firm). Thus the sharing tax limit is low at high levels of $l_{L}$. Overall $L$ is better off by setting a low ES.

Lastly, for low $s_{d}$ and sufficiently large $k$ (case $\mathrm{c}$ in Figure 4 ), $L$ cannot make positive rents by inducing sharing. The leader therefore induces undercutting to avoid negative rents. For sufficiently large $k$, attracting the clean firm dominates attracting the dirty firm for $F$ at all levels of $l_{L}$. It pays for $F$ to set the highest ES level because the clean firm's willingness to pay for it is high (if $s_{d}$ were large, a large level of $l_{L}$ would make attracting the dirty firm profitable again because of the strong repellent effect $l_{L}$ has on the dirty firm). However, since at low levels of $s_{d}$ the clean firm and the dirty firm are similar in their preferences

\footnotetext{
${ }^{30}$ This argument only holds if $k$ is not too small, which is why there is the region to the left of the wedge-shaped region b in Figure 2.
} 
and, at the highest level of $l_{F}$, the externality the dirty firm exerts on the clean firm is completely internalized, $F$ can attract the dirty firm as well without having to lower its tax substantially. Thus undercutting dominates sharing for low $s_{d}$ and large $k$.

\section{Relation to the Literature and Conclusions}

We began this paper by noting concerns in policy circles that developing countries resembling those of recent entrants to the EU may, under certain circumstances, have a second mover advantage in setting ESs and taxes. We then set out a formal framework which makes precise a set of circumstances under which such a second-mover advantage may arise. Four possible predictions were made about the outcome of fiscal competition when the public good in question is an ES. The particular prediction that emerges in equilibrium depends on the mcpe and on the difference between mobile firms in their levels of pollution captured by $s_{d}$. The model focuses on the interplay between governments' incentives to manipulate policy ESs and taxes - in order to maximize rents and firms' incentives to locate where these policies have the most favorable impact on their profits. The key point is that the government of the developed country wants to avoid inducing the developing country to undercut because that implies losing the entire tax base and hence all rents.

If the mcpe and $s_{d}$ are both low, then ESs are not important enough to firms for governments to be able to use them strategically. In this case, the forces of tax competition envisaged by Brennan and Buchanan dominate, and the outcome is efficient. If mcpe is low but $s_{d}$ is relatively high then the possibility of a pollution haven arises where the dirty firm locates in the developing country in order to escape excessively high ESs set in the developed country. If mcpe is in an intermediate range then the possibility of overprovision of ESs arises but in this region the roles of the countries are reversed; the developed country sets no ES at all, putting itself in the position of the pollution haven, while the developing country does set its ES at a positive level. For relatively high $s_{d}$ in this range the developed country is successful in attracting one firm, the dirty firm, while for low $s_{d}$ the developed country is unable to attract any firm. For mcpe at a relatively high level, the equilibrium configurations do not change from the intermediate range but the implications for efficiency do; underprovision becomes a possibility, as does efficiency.

We will now place the paper's contribution to the literature, starting with the literature that follows Tiebout (1956) and then moving on to consider the literature that parallels 
fiscal federalism and standard tax competition. As in the literature that follows Tiebout, governments in our model are rent (or profit) maximizing but are constrained by competition. For example, Fischel (1975) and White (1975) share with the present paper the assumption that there is variation over firms' preferences for standards. In keeping with our model, there are no cross-border externalities. In contrast to our model, Fischel (1975) and White (1975) both assume that individual firms can be targeted for transfers and there is 'free entry' of jurisdictions, none of which has sufficient market power to extract rents from firms. As a result, within such a setting, an efficient outcome can be demonstrated in which firms 'vote with their feet.' In our model firms cannot be targeted for transfers. There is policy failure in the sense that once the policies are set they cannot be altered. And there are only two jurisdictions. It is interesting to note that none of these differences in modeling approach matter for the achievement of efficiency providing that the mcpe and $s_{d}$ are sufficiently small. It is only when the mcpe or $s_{d}$ becomes sufficiently large for governments to compete for firms using ESs that a divergence from efficiency may arise. Given the focus on efficient outcomes in this first area of the literature and the fact that the focus tends to be on cooperative frameworks, there is limited scope in such a setting for exploring the type of second-mover advantage that is our focus in the present paper.

Let us turn now to the second area of the literature on competition over ESs and taxes, that parallels the literature on fiscal federalism and 'standard tax competition.' ${ }^{1}$ A common feature across the two areas is that jurisdictions benefit when total tax revenue is larger. Each jurisdiction attracts tax base by lowering taxes and/or ESs. In this second area of the literature, as in our model, policy makers cannot target firms for direct transfers. In contrast to the first area and also in contrast to our model, owners of the mobile resource (there capital) do not care about ESs and, seeking the highest return, tend to move their capital away from a jurisdiction if required to foot the bill for an ES. Finally, in this second area of the literature governments are benevolent and use policy to maximize the welfare of their citizens, usually including consumers, which contrasts with the first area of the literature and with our model.

In spite of the differences between the models in the second area and our model, the forces of competition between governments can operate in a similar way. This is seen most clearly by comparing the model of Markusen et al (1995) to ours. Recall that in Markusen

\footnotetext{
${ }^{31}$ This literature builds on an earlier literature, initiated by Cumberland $(1979,1981)$, that is concerned with competition between governments over environmental standards alone.
} 
et al (1995), two jurisdictions compete for the plants of a firm using two pollution taxes, one on domestic production and one on exports. The benchmark situation is one where the firm locates all its production facilities at home. Yet providing that transport costs are high enough and plant set-up costs are low enough, the foreign government can undercut the home government, much as in our model, to get some or all production to locate in its jurisdiction. The country that hosts the firm at the outset has an incentive to act in the manner of a limit-pricing monopolist, 'limit-taxing' the other country, by setting taxes just low enough that the firm is indifferent between locating its plants in one country or two and welfare is the same in both countries. (This effect is brought out most clearly by Levinson (1997), who rewrites the model of Markusen et al so that the monopoly rents are earned locally to where a plant locates.) Similarly, in our framework the developing country engages in limit-taxing by setting a tax just low enough to attract the firm(s) that it wishes to attract. In equilibrium, at least one firm is just indifferent between locating in the country that it chooses and moving to the other. Although it appears the basic underlying structure of the models in the second area of the literature could be adapted to study second mover advantage, as far as we are aware this has not been done. The standard approach is to assume that both jurisdictions are ex ante symmetrical, externalities are internalized by the agents within each jurisdiction, and governments choose policies simultaneously without communicating, yielding an outcome in which both governments obtain the same payoff in equilibrium. $^{32}$

It may be helpful to see the effects that motivate our results by direct comparison to the broader literature on fiscal competition. We are comparing the role of competition over taxes and public goods more conventionally defined against the role of competition over taxes and ESs in an environment where firms exert externalities on one another. The novel feature of competition in our model is that the developed country is compelled to set its ES and tax in such a way that it does not induce the developing country to undercut, and that this effect is strong enough to give the developing country a second-mover advantage. Our aim is to establish the novelty of this effect through comparison to the rest of the literature.

In a standard model of fiscal competition, Keen and Marchand (1997) consider a set-

\footnotetext{
${ }^{32}$ Davies and Ellis (2007) do allow for the possibility that externalities between agents within a jurisdiction are not internalized. They show that in the presence of spillovers binding performance requirements, of which ESs are a special case, can act as a coordination device for firms. In equilibrium, jurisdictions choose performance requirements that maximize joint surplus from investment, which tax competition transfers to firms via tax subsidies. Thus equilibrium is efficient and governments do not make rents.
} 
ting where the composition of public good provision matters. A jurisdiction can attract capital by increasing its productivity through a shift in spending from 'public consumption goods' such as parks and art galleries to 'public investment goods' such as road and communications networks. In this setting, competition in public good provision, which raises the return to capital that locates there, works in much the same way as tax competition. Thus, if the public good-capital complementarity is sufficiently strong, the equilibrium can exhibit over-provision of the public good in equilibrium. Although the setting of Keen and Marchand's discussion invites a consideration of agglomeration externalities they leave these forces aside. Focusing on the forces of competition over public goods alone, there seems no reason to suppose that one jurisdiction or another should derive an advantage from this kind of competition, and ex ante symmetrical jurisdictions give rise to ex ante symmetrical outcomes for the respective jurisdictions in this setting. ${ }^{33}$

Baldwin and Krugman (2004) do focus on agglomeration externalities. In their model, scale economies induce economic activity to become concentrated. Competition takes place over taxes and in equilibrium all of the (mobile) capital locates in only one jurisdiction. As in our framework, one government leads in policy-setting and the other follows. Like in Markusen et al, one jurisdiction has all the capital to begin with, and as a result it can limit-tax the other jurisdiction and keep all the capital for itself. At the same time, since agglomeration creates rents for firms that can be taxed, the forces of tax competition can lead to excessive levels of taxation (while in our model taxes are welfare neutral as they simply transfer rents from firms to the government). Unlike in Markusen et al, the government of the jurisdiction where all capital locates to begin with can skim off some of the agglomeration rents in the form of tax revenue, giving it a first-mover advantage. ${ }^{34}$

\footnotetext{
${ }^{33}$ Brueckner (2000) considers Tiebout/tax competition in an environment where firms' public good requirements vary, and shows that firms whose requirements are similar sort themselves efficiently across jurisdictions. The model of the present paper shares the feature of Tiebout-tax competition that there is variation in firms' public good requirements. Another common feature is that governments' objectives are entirely self-serving in that they are profit/rent maximizing but are constrained by competition. In contrast to Tiebout/tax competition where there is no policy failure, the policy-failure in our model does allow governments to have market power and this underpins the difference in outcome that efficiency is not achieved in equilibrium. In Brueckner's work, jurisdictions cannot make rents so in no sense can there be an advantage from the sequence in which policy decisions are taken.

${ }^{34}$ Other papers where one jurisdiction is able to limit-tax the other include Black and Hoyt (1989) and Haufler and Wooton (1999). Kind, Knarvik and Schjelderup (2000) and Boadway, Cuff and Marceau (2004) study tax competition in the presence of scale economies. Public investment goods do not usually play a role in such models. An exception is Justman, Thisse and van Ypersele (2002), who investigate the idea that under fiscal competition regions can segment the market for industrial location by offering infrastructure services that are differentiated by quality. They identify a fiscal agglomeration property, which motivates an
} 
Our model shares similarities with Bucovetsky (2005) as well. He examines an interesting situation that blends key features of previous models; many jurisdictions may compete for mobile capital in a setting where agglomeration externalities are important. To focus on the special features of competition over public investment goods, or 'public inputs' as he refers to them, he abstracts from tax competition entirely. If agglomeration externalities are sufficiently strong, the efficient solution has all of the mobile factor locating in one jurisdiction. Yet competition among jurisdictions can lead to a Nash equilibrium in which the mobile factor locates across more than one jurisdiction, in contrast to Baldwin and Krugman and similar to our model. Competition between jurisdictions can lead to overprovision of the public good as in our model. A nice feature of the model which ours does not share is that comparative statics can be carried out whereby the economies of scale can be increased by an increase in the degree of substitutability between the goods that jurisdictions produce, potentially bringing about a decrease in the number of jurisdictions that provide public investment goods in equilibrium. Our model is different in the specific mechanism by which ESs are set either excessively high or excessively low. In Bucovetsky over-provision of the public input arises as jurisdictions fail to take into account the negative externalities that an increase in the public input inflicts on other jurisdictions. In our model there are no such cross-border externalities. Instead, the developing country's second-mover advantage leads the developed country to set an inefficiently high or low ES to induce less aggressive competition by the developing country.

It is worth drawing parallels between our work and the large literature, primarily in the field of international trade, that has focused on pollution havens. The pollution haven hypothesis is that, as economies open up to each other, dirty industry will tend to become concentrated in the country with the weakest ESs. Standard international trade theory provides a natural explanation for this, which explains why it forms the cornerstone of the main explanation that is put forward for the possible existence of pollution havens. The idea is that, all else equal, thinking of pollution as an 'input' to the production process, lax ESs are a source of comparative advantage since they make the opportunity cost of pollution low. Antweiler, Copeland and Taylor (2001) construct a model around this idea and present cross-country empirical evidence that provides some support for the existence of pollution havens (also see Taylor 2004). More recent empirical work calls into question the existence asymmetric equilibrium. In these papers, if any government has an advantage in the sequence of play it is the first-mover. 
of pollution havens on the basis that the pollution content of trade flows do not appear to support the predictions of the trade model; see Ederington, Levinson and Minier (2004). Part (b) of our Theorem 1 is helpful in this regard since it presents an alternative strategic motivation for the existence of pollution havens in developing countries based on the feature of our model that the developing countries we focus on are able to respond quickly to the policies of developed countries and hence undercut them if it is profitable to do so.

Inevitably, the theoretical framework developed here simplifies the situation in a number of key respects. The most noticeable simplification we have made is that we have not explicitly treated consumers in our analysis. This is an important weakness of our approach since one of the main motivating forces for governments in setting ESs is the impact of pollution on the welfare of households. As mentioned in the Introduction, most of the prior work on governments' strategic interactions over ESs has been motivated by a desire to satisfy consumers, giving rise to the NIMBY phenomenon. A possible direction for future research would be to integrate our approach with the approach of prior work to examine the interaction of the two competing forces. One potential limitation to our result is that in no outcome does the government of the developing country set ESs 'too low.' While it seems reasonable to argue that developed countries may set ESs too high, a concern is that developing countries actually set their ESs too low from the perspective of consumers. The introduction of consumers to the model could make it possible for ESs to be set too low in the developing country.

A different potential limitation of our result is that the developing country always sets taxes higher than the developed country, which is counter-factual particularly to the core European countries versus the V4 which form our benchmark example (World Bank 1996). In the Introduction we argued that the developing country would set lower taxes if we changed the model in such a way that the mobile firms were initially located in the developed country and had an attachment to home. An alternative more interesting change to the model would be as follows. Since Keen and Marchand's work does exhibit the potential for governments to compete taxes upwards we think that a direction for future work would be to combine our framework with theirs, substituting their competition over public consumption goods with our competition over ESs. Thus in the new framework the developed country would trade off competition for firms by making them more productive but requiring them to pay higher taxes against a desire not to be undercut by the developing country. While higher 
taxation and public input provision could be observed in the developed country, a second mover advantage could be preserved in the developing country because the latter would not undertake expenditures on public inputs.

Another direction for future research would be to ask how robust our results would be to the introduction of a larger number of countries and firms to the model. From our analysis it is not obvious how the outcomes would be changed. One conjecture worth investigating would be that the $n$th country to move would always have the greatest advantage, with prior countries being constrained by those that would set policy subsequently. ${ }^{35}$

Finally, a question that could be addressed in the future is whether incentives exist for governments to coordinate/harmonize policy within our framework. Under perfect collusion in our model, governments would simply agree that neither of them would set a positive ES level and they would set taxes at the level of profits, thereby extracting all surplus. However, such perfect collusion would require a strong enforcement mechanism and, in the absence of an international enforcement body, the incentives to break such an agreement might be overwhelming. This may explain why in practice proposals for collusion have tended to be weaker, entailing for example the introduction of minimum ESs. A surprising implication of our framework is that it is not in the interest of the developed country to introduce a binding minimum ES. The reason is that the developed country benefits from being able to differentiate itself from the developing country and putting in place a minimum ES would limit the scope for doing so. Thus our model presents a possible way of understanding situations in which minimum ES levels have been called for but none have actually emerged. This issue appears to warrant further investigation in future research.

\footnotetext{
${ }^{35}$ It is tempting to think that one could analyze a model in which a 'core' country sets policy first and a larger number of periphery countries set policy subsequently (but at the same time as each other). However, the difficulty here is that in the present framework in general there may not exist an equilibrium in pure strategies when countries set policies simultaneously.
} 


\section{Appendix}

\section{Proof of Theorem 1.}

Begin with the developing country, $F$, who has four basic strategies: A) attract only the clean firm, B) attract only the dirty firm, C) attract both the clean and the dirty firm, and D) attract neither of the mobile firms.

A) To attract only the clean firm, the following two conditions must hold

$$
\begin{aligned}
\tau_{F}+k\left(1-l_{F}\right) & \leq \tau_{L}+k\left(1-l_{L}\right)\left(1+s_{d}\right) \text { and } \\
\tau_{L}+s_{d} l_{L}+k\left(1-l_{L}\right)\left(1-s_{d}\right) & <\tau_{F}+s_{d} l_{F}+k\left(1-l_{F}\right)\left(1-s_{d}\right)
\end{aligned}
$$

from where we get that

$$
\tau_{F} \in\left(\tau_{L}+\left(l_{L}-l_{F}\right)\left(s_{d}-k+k s_{d}\right), \tau_{L}+k\left(l_{F}+s_{d}-l_{L}\left(1+s_{d}\right)\right)\right] .
$$

For this interval to be nonempty we need $l_{F}>\frac{2 k l_{L}+l_{L}-k}{1+k}$. Given a standard $l_{F}$, the follower would always set the highest possible tax. Thus the optimal standard level depends on the sign of

$$
\begin{aligned}
\frac{\partial\left(\tau_{F}-l_{F}\right)}{\partial l_{F}} & =\frac{\partial\left(\tau_{L}+k\left(l_{F}+s_{d}-l_{L}\left(1+s_{d}\right)\right)-l_{F}\right)}{\partial l_{F}} \\
& =k-1,
\end{aligned}
$$

and therefore, if $k \leq 1, l_{F}=\operatorname{Max}\left\{0, \frac{2 k l_{L}+l_{L}-k}{1+k}\right\}$ and if $k>1$ then $l_{F}=1$ (but for that we need $l_{L}<1$ ). Note that at $k=1$, the follower is indifferent across all ES levels. By assumption, he chooses the lowest one. This is the same for the following cases.

B) Similarly, to attract only the dirty firm, we need

$$
\tau_{F} \in\left(\tau_{L}+k\left(l_{F}-l_{L}-s_{d}+l_{F} s_{d}\right), \tau_{L}+\left(l_{L}-l_{F}\right)\left(s_{d}-k+k s_{d}\right)\right]
$$

For this interval to be nonempty we need $l_{F}<\frac{k l_{L}+l_{L}+k}{1+2 k}$. The optimal standard level depends on the sign of

$$
\begin{aligned}
\frac{\partial\left(\tau_{F}-l_{F}\right)}{\partial l_{F}} & =\frac{\partial\left(\tau_{L}+\left(l_{L}-l_{F}\right)\left(s_{d}-k+k s_{d}\right)-\left(1+s_{d}\right) l_{F}\right)}{\partial l_{F}} \\
& =-2 s_{d}+k\left(1-s_{d}\right)-1
\end{aligned}
$$

and therefore, if $k \leq \frac{1+2 s_{d}}{1-s_{d}}$, then $l_{F}=0$, and if $k>\frac{1+2 s_{d}}{1-s_{d}}$, then $l_{F}=\frac{k l_{L}+l_{L}+k}{1+2 k}$. 
C) To attract both mobile firms, we need

$$
\begin{aligned}
\tau_{F} & \leq \operatorname{Min}\left\{\tau_{F}^{1}, \tau_{F}^{2}\right\} \\
& \equiv \operatorname{Min}\left\{\tau_{L}+k\left(l_{F}-l_{L}-s_{d}+l_{F} s_{d}\right), \tau_{L}+\left(l_{L}-l_{F}\right)\left(s_{d}-k+k s_{d}\right)\right\}
\end{aligned}
$$

We have $\tau_{F}^{1} \leq \tau_{F}^{2} \Leftrightarrow l_{F} \leq \frac{k l_{L}+l_{L}+k}{1+2 k}$. Given a standard $l_{F}$, the optimal tax is $\tau_{F}=$ $\operatorname{Min}\left\{\tau_{F}^{1}, \tau_{F}^{2}\right\}$.

Case 1: $l_{F} \leq \frac{k l_{L}+l_{L}+k}{1+2 k}$

$$
\begin{aligned}
\frac{\partial\left(2 * \tau_{F}^{1}-\left(1+s_{d}\right) l_{F}\right)}{\partial l_{F}} & =\frac{\partial\left(2 \tau_{L}+2 k\left(l_{F}-l_{L}-s_{d}+l_{F} s_{d}\right)-\left(1+s_{d}\right) l_{F}\right)}{\partial l_{F}} \\
& =2 k\left(1+s_{d}\right)-\left(1+s_{d}\right)
\end{aligned}
$$

and therefore, if $k \leq \frac{1}{2}$, then $l_{F}=0$, and if $k>\frac{1}{2}$, then $l_{F}=\frac{k l_{L}+l_{L}+k}{1+2 k}$.

Case 2: $l_{F} \geq \frac{k l_{L}+l_{L}+k}{1+2 k}$

$$
\begin{aligned}
\frac{\partial\left(2 * \tau_{F}^{2}-\left(1+s_{d}\right) l_{F}\right)}{\partial l_{F}} & =\frac{\partial\left(2 \tau_{L}+2\left(l_{L}-l_{F}\right)\left(s_{d}-k+k s_{d}\right)-\left(1+s_{d}\right) l_{F}\right)}{\partial l_{F}} \\
& =-3 s_{d}-1+2 k\left(1-s_{d}\right),
\end{aligned}
$$

and therefore, if $k \leq \frac{1+3 s_{d}}{2\left(1-s_{d}\right)}$, then $l_{F}=\frac{k l_{L}+l_{L}+k}{1+2 k}$, and if $k>\frac{1+3 s_{d}}{2\left(1-s_{d}\right)}$, then $l_{F}=1$. Putting the two cases together we obtain

$$
\begin{aligned}
& l_{F}=0 \text { and } \tau_{F}^{1} \text { if } k \leq \frac{1}{2}, \\
& l_{F}=\frac{k l_{L}+l_{L}+k}{1+2 k} \text { and } \tau_{F}^{1}=\tau_{F}^{2} \text { if } k \in\left(\frac{1}{2}, \frac{1+3 s_{d}}{2\left(1-s_{d}\right)}\right], \text { and } \\
& l_{F}=1 \text { and } \tau_{F}^{2} \text { if } k>\frac{1+3 s_{d}}{2\left(1-s_{d}\right)} .
\end{aligned}
$$

D) By setting a sufficiently high tax, $F$ deters both mobile firms, earning zero rents. This never happens in equilibrium as the following argument shows. Note that rents in $\mathrm{C}$ are higher than in $\mathrm{A}$ or $\mathrm{B}$ for sufficiently large $\tau_{L}$ (the maximum taxes in $\mathrm{A}, \mathrm{B}$, and $\mathrm{C}$ increase by the same rate in $\tau_{L}$ and in $\mathrm{C}$ this tax is collected twice). Thus $L$ can always induce $\mathrm{C}$ and make zero rents. Therefore, in equilibrium, $L$ sets a tax that covers the costs of monitoring the standard. It is easy to show that for any $\tau_{L}$ sufficiently large to do that, $F$ has at least one strategy (in A, B, or C) that makes positive rents, showing that $F$ never chooses D.

The next step is to compare F's rents across A, B, and C. According to the results so far, there are five different ranges of $k$ to consider: If $s_{d}<\frac{1}{5}$, these are I) $k \leq \frac{1}{2}$, II) 
$\left.\left.k \in\left(\frac{1}{2}, \frac{1+3 s_{d}}{2\left(1-s_{d}\right)}\right], \mathrm{III}\right) k \in\left(\frac{1+3 s_{d}}{2\left(1-s_{d}\right)}, 1\right], \mathrm{IV}\right) k \in\left(1, \frac{1+2 s_{d}}{1-s_{d}}\right]$, and V) $k>\frac{1+2 s_{d}}{1-s_{d}}$, and if $s_{d} \geq \frac{1}{5}$, these are I') $k \leq \frac{1}{2}$, II') $k \in\left(\frac{1}{2}, 1\right]$, III') $k \in\left(1, \frac{1+3 s_{d}}{2\left(1-s_{d}\right)}\right]$, IV') $k \in\left(\frac{1+3 s_{d}}{2\left(1-s_{d}\right)}, \frac{1+2 s_{d}}{1-s_{d}}\right]$, and V') $k>\frac{1+2 s_{d}}{1-s_{d}}$.

I and I') $k \leq \frac{1}{2}$. Rents in each case are.

$$
\begin{aligned}
& r_{A}=\left\{\begin{array}{cc}
\tau_{L}+k\left(s_{d}-l_{L}\left(1+s_{d}\right)\right) & \text { if } l_{L}<\frac{k}{2 k+1} \\
\tau_{L}+k\left(\frac{2 k l_{L}+l_{L}-k}{1+k}+s_{d}-l_{L}\left(1+s_{d}\right)\right)-\frac{2 k l_{L}+l_{L}-k}{1+k} & \text { if } l_{L} \geq \frac{k}{2 k+1}
\end{array}\right. \\
& r_{B}=\tau_{L}+l_{L}\left(s_{d}-k+k s_{d}\right), \text { and } \\
& r_{C}=2 \tau_{L}-2 k\left(l_{L}+s_{d}\right) .
\end{aligned}
$$

For $l_{L} \leq \frac{k}{2 k+1}$, we have $r_{A} \geq r_{B}$ and for $l_{L}>\frac{k}{2 k+1}$ we have $r_{B}>r_{A}$ (if $r_{A}=r_{B}, F$ chooses $A$ by assumption). Next, compare $r_{A}$ with $r_{C}$ for $l_{L} \leq \frac{k}{2 k+1}$ and $r_{B}$ with $r_{C}$ for $l_{L}>\frac{k}{2 k+1}$. This comparison yields

$$
\begin{aligned}
& r_{A} \geq r_{C} \Leftrightarrow \tau_{L} \leq k\left(l_{L}+3 s_{d}-l_{L} s_{d}\right), \text { and } \\
& r_{B} \geq r_{C} \Leftrightarrow \tau_{L} \leq k l_{L}+2 k s_{d}+l_{L} s_{d}+k l_{L} s_{d} .
\end{aligned}
$$

Thus, for each case there is a sharing tax limit, an upper bound on the tax the leader can set without having the follower 'undercut' him. We denote this limit by $\hat{\tau}_{L}\left(l_{L} ; k, s_{d}\right)$.

For the remaining ranges of $k$, the derivation is as in (I and I'), so we omit the details:

II and II') $k \in\left(\frac{1}{2}, \operatorname{Min}\left\{\frac{1+3 s_{d}}{2\left(1-s_{d}\right)}, 1\right\}\right]$. The sharing tax limit in this range of $k$ is given by $\hat{\tau}_{L}\left(l_{L} ; k, s_{d}\right)=$

$$
\left\{\begin{array}{c}
(2 k+1)^{-1}\left(k+l_{L}+4 k s_{d}+l_{L} s_{d}-2 k l_{L} s_{d}-2 k^{2}+4 k^{2} s_{d}-4 k^{2} l_{L} s_{d}\right) \\
(2 k+1)^{-1}\left(k+l_{L}+3 k s_{d}+2 l_{L} s_{d}+2 k l_{L} s_{d}-2 k^{2}+2 k^{2} s_{d}\right)
\end{array} \quad \text { if } \begin{array}{c}
l_{L} \leq \frac{k}{2 k+1} \\
l_{L}>\frac{k}{2 k+1}
\end{array} .\right.
$$

III) $k \in\left(\frac{1+3 s_{d}}{2\left(1-s_{d}\right)}, 1\right]$. Here, $\hat{\tau}_{L}\left(l_{L} ; k, s_{d}\right)=$

$$
\left\{\begin{array}{c}
3 s_{d}-2 k+k l_{L}+3 k s_{d}-2 l_{L} s_{d}-3 k l_{L} s_{d}+1 \\
3 s_{d}-2 k+k l_{L}+2 k s_{d}-l_{L} s_{d}-k l_{L} s_{d}+1
\end{array} \text { if } \begin{array}{c}
l_{L} \leq \frac{k}{2 k+1} \\
l_{L}>\frac{k}{2 k+1}
\end{array} .\right.
$$

III') $k \in\left(1, \frac{1+3 s_{d}}{2\left(1-s_{d}\right)}\right]$. Here, $\hat{\tau}_{L}\left(l_{L} ; k, s_{d}\right)=$

$$
\left\{\begin{array}{c}
-(2 k+1)^{-1}\left(2 k l_{L} s_{d}-4 k s_{d}-l_{L} s_{d}-l_{L}-4 k^{2} s_{d}+4 k^{2} l_{L} s_{d}+1\right) \\
(2 k+1)^{-1}\left(k+l_{L}+3 k s_{d}+2 l_{L} s_{d}+2 k l_{L} s_{d}-2 k^{2}+2 k^{2} s_{d}\right)
\end{array} \quad \text { if } \quad \begin{array}{c}
l_{L} \leq \frac{-1+k+k s_{d}}{s_{d}(1+2 k)} \\
l_{L}>\frac{-1+k+k s_{d}}{s_{d}(1+2 k)}
\end{array} .\right.
$$


IV and IV') $k \in\left(\operatorname{Max}\left\{\frac{1+3 s_{d}}{2\left(1-s_{d}\right)}, 1\right\}, \frac{1+2 s_{d}}{1-s_{d}}\right]$. Here, $\hat{\tau}_{L}\left(l_{L} ; k, s_{d}\right)=$

$$
\left\{\begin{array}{ccc}
-\left(k-3 s_{d}-k l_{L}-3 k s_{d}+2 l_{L} s_{d}+3 k l_{L} s_{d}\right) & \text { if } & l_{L} \leq \frac{-1+k+k s_{d}}{s_{d}(1+2 k)} \\
3 s_{d}-2 k+k l_{L}+2 k s_{d}-l_{L} s_{d}-k l_{L} s_{d}+1 & l_{L}>\frac{-1+k+k s_{d}}{s_{d}(1+2 k)}
\end{array} .\right.
$$

V) and $\left.\mathbf{V}^{\prime}\right) k>\frac{1+2 s_{d}}{1-s_{d}}$. In this range of $k$, we have $r_{A}>r_{B}$ for all $l_{L}<1$ and the sharing tax limit is given by $\hat{\tau}_{L}\left(l_{L} ; k, s_{d}\right)=$

$$
-\left(k-3 s_{d}-k l_{L}-3 k s_{d}+2 l_{L} s_{d}+3 k l_{L} s_{d}\right) .
$$

Here, if $l_{L}=1$, then $A$ is not feasible for $F$. Thus for $l_{L}=1$ we compare $r_{B}$ with $r_{C}$, which yields $\hat{\tau}_{L}\left(l_{L} ; k, s_{d}\right)=0$. We can ignore this case in the following since we have already established that $L$ makes at least zero rents.

Now consider the developed country, $L$. Since $F$ 's optimal response depends on the value of $k$, we need to consider $L$ 's problem for each of the cases I-IV (I'-V'). To make positive rents $L$ tries to induce $F$ to choose a strategy in $\mathrm{A}$ or $\mathrm{B}$. The maximum tax $L$ can set at a given ES level is the corresponding sharing tax limit. It only remains to determine $L$ 's optimal ES level. Except for V and V', the sharing tax limit has one discontinuity, where $F$ switches from A to B. We derive the optimal ES level in three steps. First determine, what are the optimal ES levels to induce A and to induce B, second, compare rents at these levels, and third determine when $L$ 's rents are negative. In this case, $L$ induces $\mathrm{C}$ by setting $l_{L}=0$ and some tax $\tau_{L}$ above the corresponding sharing tax limit.

I and I') $k \leq \frac{1}{2}$.

(i) $l_{L} \leq \frac{k}{2 k+1}$. To determine the optimal ES level, consider the sign of

$$
\begin{aligned}
\frac{\partial\left(\hat{\tau}_{L}\left(l_{L} ; k, s_{d}\right)-\left(1+s_{d}\right) l_{L}\right)}{\partial l_{L}} & =\frac{\partial\left(k\left(l_{L}+3 s_{d}-l_{L} s_{d}\right)-\left(1+s_{d}\right) l_{L}\right)}{\partial l_{L}} \\
& =k-s_{d}-k s_{d}-1 .
\end{aligned}
$$

Thus, conditional on $l_{L} \leq \frac{k}{2 k+1}$ and in the relevant range of $k$, the leader sets $l_{L}=0$.

(ii) $l_{L}>\frac{k}{2 k+1}$. Consider the sign of

$$
\begin{aligned}
\frac{\partial\left(\hat{\tau}_{L}\left(l_{L} ; k, s_{d}\right)-l_{L}\right)}{\partial l_{L}} & =\frac{\partial\left(k l_{L}+2 k s_{d}+l_{L} s_{d}+k l_{L} s_{d}-l_{L}\right)}{\partial l_{L}} \\
& =k+s_{d}+k s_{d}-1 .
\end{aligned}
$$

Thus, conditional on $l_{L}>\frac{k}{2 k+1}$ and $k \leq \frac{1-s_{d}}{1+s_{d}}$ the leader sets $l_{L}=\frac{k}{2 k+1}$, and if $k>\frac{1-s_{d}}{1+s_{d}}$ the leader sets $l_{L}=1$. (We ignore for the moment that $l_{L}=\frac{k}{2 k+1}$ is not in the relevant interval for 
$l_{L}$. This does not play a role because when comparing rents in (i) and (ii) $l_{L}=\frac{k}{2 k+1}$ is never chosen even though, for any $\varepsilon>0$, it yields slightly higher rents than setting $l_{L}=\frac{k}{2 k+1}+\varepsilon$ ). If indifferent, $L$ chooses the lower ES level by assumption.

Comparing rents in (i) and (ii) yields that for $k \leq 1-s_{d}$, the leader induces $A$, and otherwise $B$. We obtain

$$
\begin{aligned}
\text { If } k & \leq 1-s_{d}, \\
l_{L}^{*} & =0, \tau_{L}^{*}=3 k s_{d} \text { and } l_{F}^{*}=0, \tau_{F}^{*}=4 k s_{d} . \\
\text { If } k & >1-s_{d}, \\
l_{L}^{*} & =1, \tau_{L}^{*}=k+3 k s_{d}+s_{d} \text { and } l_{F}^{*}=0, \tau_{F}^{*}=4 k s_{d}+2 s_{d} .
\end{aligned}
$$

For the remaining ranges of $k$, the derivation is as in (I and I'), so we omit the details: II and II') $k \in\left(\frac{1}{2}, \operatorname{Min}\left\{\frac{1+3 s_{d}}{2\left(1-s_{d}\right)}, 1\right\}\right]$. We obtain

$$
\begin{aligned}
\text { If } k & <\frac{1}{4} s_{d}^{-1}\left(s_{d}+\sqrt{16 s_{d}^{2}+\left(2-s_{d}\right)^{2}}-2\right), \\
l_{L}^{*} & =1, \tau_{L}^{*}=(2 k+1)^{-1}\left(k+1+5 k s_{d}+2 s_{d}-2 k^{2}+2 k^{2} s_{d}\right), \text { and } \\
l_{F}^{*} & =0, \tau_{F}^{*}=(2 k+1)^{-1}\left(k+1+5 k s_{d}+2 s_{d}-2 k^{2}+2 k^{2} s_{d}\right)+\left(s_{d}-k+k s_{d}\right) . \\
\text { If } k & \geq \frac{1}{4} s_{d}^{-1}\left(s_{d}+\sqrt{16 s_{d}^{2}+\left(2-s_{d}\right)^{2}}-2\right), \\
l_{L}^{*} & =0, \tau_{L}=(2 k+1)^{-1}\left(k+4 k s_{d}-2 k^{2}+4 k^{2} s_{d}\right), \text { and } \\
l_{F}^{*} & =0, \tau_{F}=(2 k+1)^{-1}\left(k+4 k s_{d}-2 k^{2}+4 k^{2} s_{d}\right)+k s_{d} .
\end{aligned}
$$

III) $k \in\left(\frac{1+3 s_{d}}{2\left(1-s_{d}\right)}, 1\right]$. We obtain

$$
\begin{aligned}
& l_{L}^{*}=0, \tau_{L}^{*}=3 s_{d}-2 k+3 k s_{d}+1, \text { and } \\
& l_{F}^{*}=0, \tau_{F}^{*}=3 s_{d}-2 k+3 k s_{d}+1+k s_{d} .
\end{aligned}
$$

III') $k \in\left(1, \frac{1+3 s_{d}}{2\left(1-s_{d}\right)}\right]$. We obtain

$$
\begin{aligned}
& l_{L}^{*}=0, \tau_{L}^{*}=(2 k+1)^{-1}\left(4 k s_{d}+4 k^{2} s_{d}-1\right), \text { and } \\
& l_{F}^{*}=1, \tau_{F}^{*}=(2 k+1)^{-1}\left(4 k s_{d}+4 k^{2} s_{d}-1\right)+k\left(1+s_{d}\right) .
\end{aligned}
$$

IV and IV') $k \in\left(\operatorname{Max}\left\{\frac{1+3 s_{d}}{2\left(1-s_{d}\right)}, 1\right\}, \frac{1+2 s_{d}}{1-s_{d}}\right]$. We obtain

$$
\begin{aligned}
& l_{L}^{*}=0, \tau_{L}^{*}=3 s_{d}+3 k s_{d}-k \\
& l_{F}^{*}=1, \tau_{F}^{*}=3 s_{d}+4 k s_{d} .
\end{aligned}
$$


V) and $\left.\mathbf{V}^{\prime}\right) k>\frac{1+2 s_{d}}{1-s_{d}}$

Consider the sign of

$$
\frac{\partial\left(\hat{\tau}_{L}\left(l_{L} ; k, s_{d}\right)-\left(1+s_{d}\right) l_{L}\right)}{\partial l_{L}}=k-3 s_{d}-3 k s_{d}-1 .
$$

Therefore if $s_{d} \geq \frac{1}{3}$ or if $k \leq \frac{1+3 s_{d}}{1-3 s_{d}}$ (only possible if $s_{d}<\frac{1}{3}$ ) the leader sets $l_{L}=0$ and if $s_{d}<\frac{1}{3}$ and $k>\frac{1+3 s_{d}}{1-3 s_{d}}$ the leader sets $l_{L}=1$ (however, for $l_{L}=1, A$ is not feasible for $F$, but this does not matter since we have already excluded this case). We obtain (for now and ignoring the problem at $l_{L}=1$ )

$$
\begin{aligned}
\text { If } s_{d} & \geq \frac{1}{3} \text { or if } k \leq \frac{1+3 s_{d}}{1-3 s_{d}}, \\
l_{L}^{*} & =0, \tau_{L}^{*}=3 s_{d}+3 k s_{d}-k \text { and } l_{F}^{*}=1, \tau_{F}^{*}=3 s_{d}+4 k s_{d} . \\
\text { If } s_{d} & <\frac{1}{3} \text { and } k>\frac{1+3 s_{d}}{1-3 s_{d}}, \\
l_{L}^{*} & =1, \tau_{L}^{*}=s_{d} \text { and } l_{F}^{*}=1, \tau_{F}^{*}=s_{d} .
\end{aligned}
$$

If $L$ 's rents are negative, it is better off setting $l_{L}=0$ and a 'deterring tax' of $\tau_{L}^{d}>$ $\hat{\tau}_{L}\left(0 ; k, s_{d}\right)$ to induce $F$ to undercut, thereby ensuring zero rents. This happens if $k \leq 1$ and $s_{d}<\frac{2 k-1}{3(k+1)}$ and if $k>1$ and $s_{d}<\frac{k}{3(k+1)}$. In these cases $F$ 's best response is to set $l_{F}=1$ and $\tau_{F}=\tau_{L}^{d}-\left(s_{d}-k+k s_{d}\right)$.

Given these equilibrium strategies, it is straightforward to verify that there is always a second-mover advantage. 


\section{References}

[1] Andanova, L.B. (2003); Transnational Politics of the Environment: The European Union and Environmental Policy in Central and Eastern Europe. MIT Press, Cambridge, MA.

[2] Antweiler, A., B. Copeland and M.S. Taylor (2001); "Is Free Trade Good for the Environment?" American Economic Review, 91(4): 877-908.

[3] Baldwin, R. and P. Krugman (2004); "Agglomeration, Integration and Tax Harmonization." European Economic Review, 48: 1-23.

[4] Black, D.A. and W.H. Hoyt (1989); "Bidding for Firms." American Economic Review, 79(5): 1249-1256.

[5] Boadway, R., K. Cuff and N. Marceau (2004); "Agglomeration Effects and the Competition for Firms." International Tax and Public Finance 11: 623-646.

[6] Brennan, G. and J.M. Buchanan, (1980); The Power To Tax: Analytical Foundations of a Fiscal Constitution, Cambridge University Press, Cambridge.

[7] Brueckner, J.K. (2000); "A Tiebout/Tax Competition Model." Journal of Public Economics 77: 285-306.

[8] Cumberland, J.H. (1979); "Interregional Pollution Spillovers and Consistency of Environmental Policy." Published in H. Siebert et al. eds., Regional Environmental Policy: The Economic Issues, New York University Press, New York.

[9] Cumberland, J.H. (1981); "Efficiency and Equity in Interregional Environmental Management." Review of Regional Studies 2: 1-9.

[10] Davies, R.B. and C.J. Ellis (2007); Competition in Taxes and Performance Requirements for Foreign Direct Investment." European Economic Review, 51(5): 1303-1325.

[11] Ederington, J., A. Levinson and J. Minier (2004); "Trade Liberalization and Pollution Havens." Published in Advances in Economic Analysis and Policy, Vol. 4, No. 2, Article 6, the Berkley Electronic Press. 
[12] Euractiv (2010); "Commission proposes phasing out coal subsidies." http://www.euractiv.com/en/energy/commission-proposes-phasing-out-coal-subsidiesnews-496532, published on July 21, 2010, last accessed on September 29, 2010.

[13] Fischel, W.A. (1975); "Fiscal and Environmental Considerations in the Location of Firms in Suburban Communities." Published in E. Mills and W. Oates (eds.) Fiscal Zoning and Land Use Controls, D.C. Heath, Lexington, MA.

[14] Haufler, A. and I. Wooton (1999); "Country Size and Tax Competition for Foreign Direct Investment." Journal of Public Economics, 71: 121-139.

[15] Justman, M., J.-F. Thisse, and T. van Ypersele (2002); "Taking the Bite out of Fiscal Competition." Journal of Urban Economics 52, 294-315.

[16] Keen, M. and M. Marchand (1997); "Fiscal Competition and the Pattern of Public Spending." Journal of Public Economics 66: 33-53.

[17] Kind, H., K. Knarvik and G. Schjelderup (2000); "Competing for Capital in a 'Lumpy' World." Journal of Public Economics, 78: 253-274.

[18] Levinson, A. (1997); "A Note on Environmental Federalism: Interpreting Some Contradictory Results." Journal of Environmental Economics and Management 33: 359-366.

[19] Levinson, A. (1999a); "NIMBY Taxes Matter: the Case of State Hazardous Waste Disposal Taxes." Journal of Public Economics 74: 31-51.

[20] Levinson, A. (1999b); "State Taxes and Interstate Hazardous Waste Shipments." American Economic Review, 89(3): 666-677.

[21] Levinson, A. (2003); "Environmental Regulatory Competition: A Status Report and Some New Evidence." National Tax Journal, 56(1): 91-106.

[22] Markusen, J.R., E.R. Morey and N. Olewiler (1995); "Competition in Regional Environmental Policies When Plant Locations are Endogenous." Journal of Public Economics, 56: 55-77.

[23] New York Times (2010); "Europe's Enduring Coal Subsidies." http://green.blogs.nytimes.com/2010/06/28/europes-enduring-coal-subsidies/, article by J. Kanter, published on June 28, 2010, last accessed on October 7, 2010. 
[24] Oates, W.E. (1972); Fiscal Federalism, Harcourt Brace Jovanovich, New York.

[25] Oates, W.E. and R.M. Schwab (1988); "Economic Competition Among Jurisdictions: Efficiency Enhancing or Distortion Inducing?" Journal of Public Economics, 35: 333-354

[26] Post, D. (2002); "Closing the Deception Gap: Accession to the European Union and Environmental Standards in East Central Europe." Published in University of California International and Area Studies (UCIAS) Edited Volume 1: Dynamics of Regulatory Change: How Globalization Affects National Regulatory Policies. Berkeley Electronic Press.

[27] Taylor, M.S. (2004); "Unbundling the Pollution Haven Hypothesis." Published in Advances in Economic Analysis and Policy, the Berkley Electronic Press.

[28] White, M.J. (1975); "Firm Location in a Zoned Metropolitan Area." Published in E.S. Mills and W.E. Oates (eds.) Fiscal Zoning and Land Use Controls, D.C. Heath, Lexington, MA.

[29] Wilson, J.D. (1986); "A Theory of Interregional Tax Competition Journal of Urban Economics, 19: 296-315.

[30] Wilson, J.D. (1996); "Capital Mobility and Environmental Standards: Is There a Theoretical Case for a Race to the Bottom?" Chapter 10 in Fair Trade and Harmonization by J.N. Bhagwati and R.E. Hudec. MIT Press, Cambridge.

[31] Zodrow, G.R. and P. Mieszkowski (1986); "Pigou, Tiebout, Property Taxation and the Under-Provision of Local Public Goods." Journal of Urban Economics, 19: 356-370. 